\title{
NIST Special Publication 1126
}

\section{Summary of Full-scale Experiments to Determine Vulnerabilities of Building Components to Ignition by Firebrand Showers}

Samuel L. Manzello

Sayaka Suzuki

Yoshihiko Hayashi

National Institute of Standards and Technology • U.S. Department of Commerce 


\title{
NIST Special Publication 1126
}

\section{Summary of Full-scale Experiments to Determine Vulnerabilities of Building Components to Ignition by Firebrand Showers}

\author{
Samuel L. Manzello \\ Sayaka Suzuki \\ Fire Research Division \\ Engineering Laboratory \\ Yoshihiko Hayashi \\ Department of Fire Engineering \\ Building Research Institute
}

December 2011

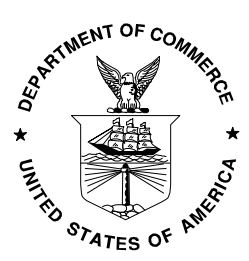

U.S. Department of Commerce John E. Bryson, Secretary

National Institute of Standards and Technology Patrick D. Gallagher, Under Secretary for Standards and Technology and Director 
Certain commercial entities, equipment, or materials may be identified in this document in order to describe an experimental procedure or concept adequately. Such identification is not intended to imply recommendation or endorsement by the National Institute of Standards and Technology, nor is it intended to imply that the entities, materials, or equipment are necessarily the best available for the purpose.

National Institute of Standards and Technology Special Publication 1126

Natl. Inst. Stand. Technol. Spec. Publ. 1126, 56 pages (December 2011)

CODEN: NSPUE2 


\section{Table of contents}

Abstract $\quad$ iv

$\begin{array}{ll}1.0 \text { Introduction } & 1\end{array}$

$\begin{array}{lc}2.0 \text { NIST Firebrand Generator (NIST Dragon) } & 2\end{array}$

$\begin{array}{lr}3.0 \text { Roofing Vulnerabilities } & 8\end{array}$

$\begin{array}{ll}\text { 4.0 Building Vent Vulnerabilities } & 15\end{array}$

$\begin{array}{ll}\text { 5.0 Siding Treatment Vulnerabilities } & 25\end{array}$

$\begin{array}{ll}\text { 6.0 Eave Vulnerabilities } & 31\end{array}$

$\begin{array}{ll}\text { 7.0 Glazing Assembly Vulnerabilities } & 36\end{array}$

8.0 Firebrand Accumulation in Front of Obstacles 38

9.0 Firebrand Production from Burning Structures and Structure Components 42

10.0 General Remarks, Future Research, and Summary $\quad 51$

$\begin{array}{lll}11.0 & \text { Acknowledgements } & 53\end{array}$

$\begin{array}{lll}12.0 & \text { References } & 53\end{array}$ 


\begin{abstract}
Wind driven firebrand showers are a major cause of structural ignition in Wildland-Urban Interface (WUI) fires in the USA and urban fires in Japan. For over 40 years, past firebrand studies have focused on understanding how far firebrands fly (spotting distance). These firebrand transport studies do not assess the vulnerabilities of structures to ignition from firebrand attack and are of limited use to develop ignition resistant structures. Building codes and standards are needed to guide construction of new structures in areas known to be prone to these fires in order to reduce the risk of structural ignition in the event of a firebrand attack. Proven, scientifically based retrofitting strategies are required for homes located in areas prone to such fires. To meet these objectives requires knowledge regarding the types of materials that can be ignited by firebrands as well as vulnerable points on a structure where firebrands may easily enter. In order to do this, a unique experimental apparatus, known as the NIST Firebrand Generator, has been constructed to generate controlled, repeatable firebrand showers commensurate to those measured from burning conifers and a real WUI fire. Since wind plays a critical role in the spread of WUI fires in the USA and urban fires in Japan, NIST has established collaboration with the Building Research Institute (BRI) in Japan. BRI maintains one of the only full-scale wind tunnel facilities in the world designed specifically for fire experimentation; the Fire Research Wind Tunnel Facility (FRWTF). This report brings together all of the full-scale experimental results conducted by NIST using BRI's FRWTF to date.
\end{abstract}




\subsection{Introduction}

Structure ignition in the Wildland-Urban Interface (WUI) is a significant international problem with major WUI fires reported in Australia, Greece, Portugal, Spain, and the USA. There have been three significant WUI fires within the past six years in the State of California in the USA. The recent fires in Victoria, Australia in 2009 resulted in over 150 deaths and more than three thousand destroyed structures.

Evidence suggests that wind driven firebrand showers are a major cause of structural ignition in WUI fires in the USA and Australia [1-3]. Japan has been plagued by structural ignition from firebrand showers in urban fires. Building codes and standards are needed to guide construction of new structures in areas known to be prone to these fires in order to reduce the risk of structural ignition in the event of a firebrand attack. Proven, scientifically based retrofitting strategies are required for homes that already exist in areas prone to such fires. To meet these objectives requires knowledge regarding the types of materials that can be ignited by firebrands as well as vulnerable points on a structure where firebrands may easily enter.

For over 40 years, past firebrand studies have focused on understanding how far firebrands fly (spotting distance); these studies do not assess the vulnerabilities of structures to ignition from firebrand attack and are of limited use to develop ignition resistant structures [414]. It is difficult to develop measurement methods to replicate wind driven firebrand bombardment on structures that occur in actual WUI and urban fires. Entirely new experimental approaches are required to address this problem.

In order to do this, a unique experimental apparatus, known as the NIST Firebrand Generator, has been constructed to generate controlled, repeatable firebrand showers commensurate to those measured from burning conifers and a real WUI fire. Since wind plays a 
critical role in the spread of WUI fires in the USA and urban fires in Japan, NIST has established collaboration with the Building Research Institute (BRI) in Japan. BRI maintains one of the only full-scale wind tunnel facilities in the world designed specifically for fire experimentation; the Fire Research Wind Tunnel Facility (FRWTF).

Two mechanisms are responsible for structural ignition from wind driven firebrand showers: penetration of firebrands inside the structure (such as building vents) and ignition of materials on the exterior of the structure (such as siding treatments or mulch). The coupling of the NIST Firebrand Generator and BRI's FRWTF has enabled the study of both types of vulnerabilities for the first time [15-18].

In this report, a summary of key results focused on determining these vulnerabilities is delineated. Specifically, results are presented on parametric studies that were focused on exposing roofing assemblies, building vents, siding treatments, walls fitted with eaves, and glazing assemblies to firebrand showers. The danger of firebrand accumulation in front of structures is presented. Results of recent experiments focused on firebrand generation from structures are summarized as well. This report brings together all of the full-scale experimental results conducted by NIST regarding firebrands since 2007.

\subsection{NIST Firebrand Generator (NIST Dragon)}

Figure 1 is a drawing of the NIST Firebrand Generator. A brief description of the device is provided here since a detailed description has been provided elsewhere [15- 18]. This version of the device was scaled up from a first-generation, proof-of-concept Firebrand Generator [19]. The bottom panel displays the procedure for loading tree mulch into the apparatus. Tree mulch is used as the fuel source to generate firebrands (details follow below). 


\section{Firebrand Generator Assembled Side View}

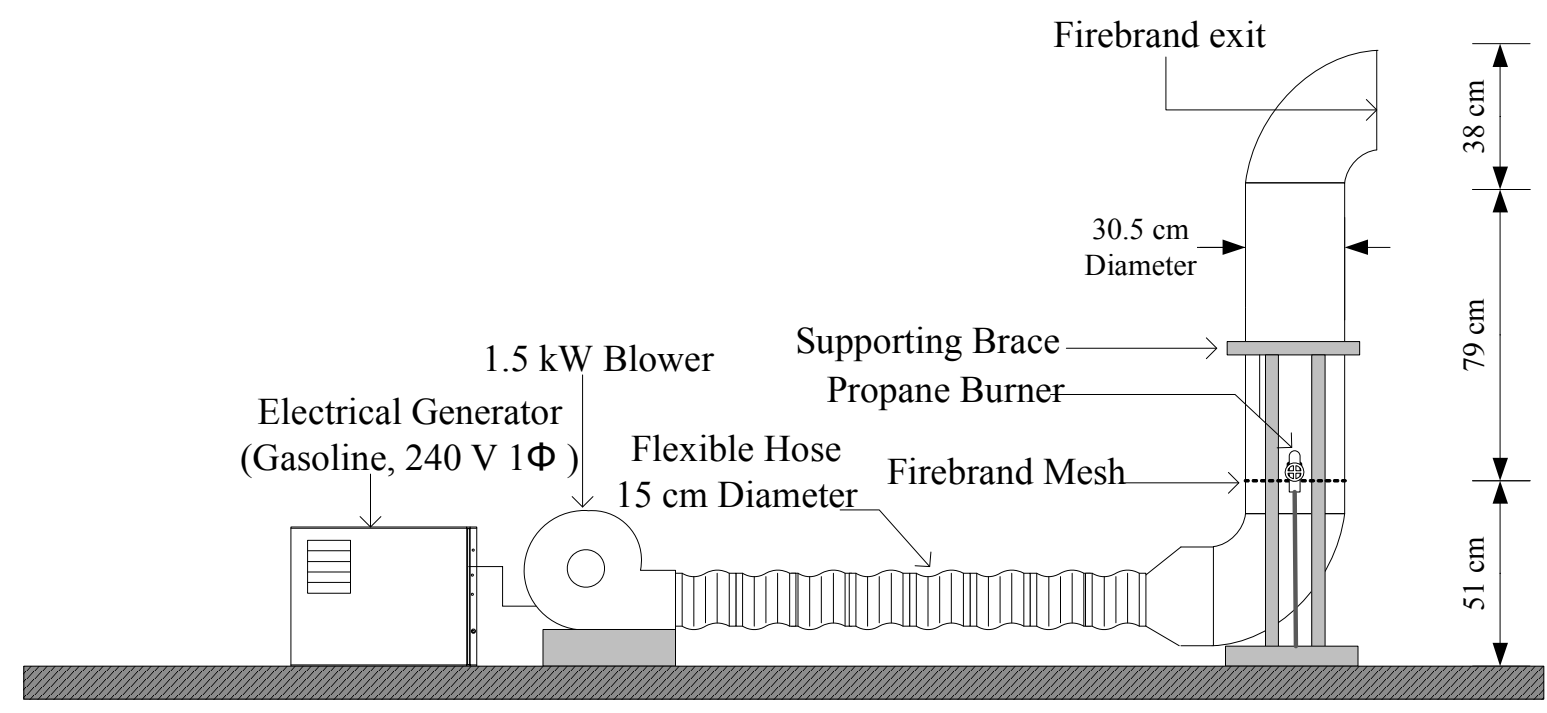

Firebrand Generator Disassembled

To Load Firebrands

Front View

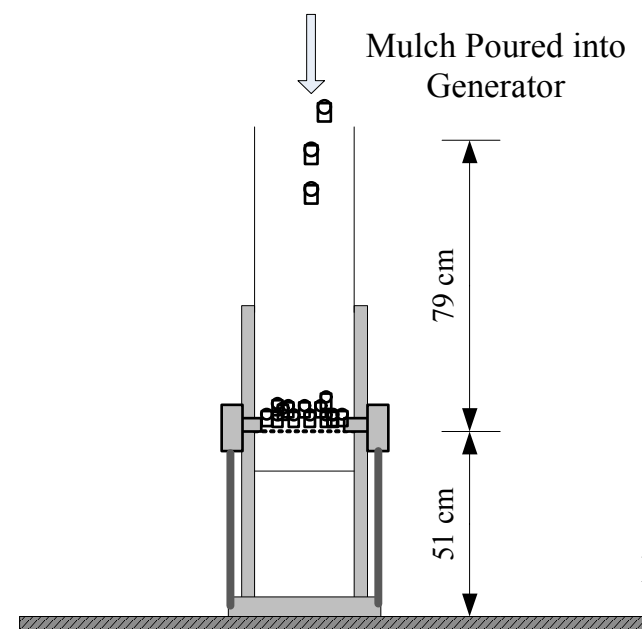

Firebrand Generator Assembled Front View

Firebrand exit

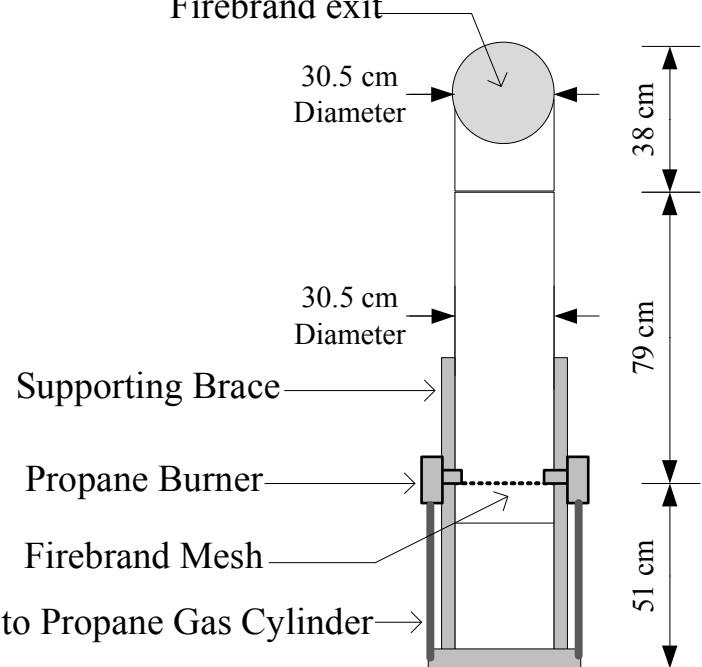

Figure 1 Schematic of NIST Firebrand Generator (NIST Dragon).

The mulch pieces were deposited into the Firebrand Generator by removing the top portion. The mulch pieces were supported using a stainless steel mesh screen $(0.35 \mathrm{~cm} \mathrm{spacing})$, which was carefully selected. Two different screens were used to filter the mulch pieces prior to loading into the firebrand generator. The first screen blocked all mulch pieces larger than $25 \mathrm{~mm}$ 
in diameter. A second screen was then used to remove all needles from the mulch pieces. The justification for this filtering methodology is provided below. The maximum mulch loading possible with the current Firebrand Generator design is $2.8 \mathrm{~kg}$. The firebrand generator was driven by a $1.5 \mathrm{~kW}$ blower.

After the tree mulch was loaded, the top section of the Firebrand Generator was coupled to the main body of the apparatus. The blower was then switched to provide a low flow for ignition. The two propane burners were then ignited individually and simultaneously inserted into the opposite sides of the generator. This sequence of events was selected in order to generate a continuous flow of glowing firebrands for up to six minutes duration.

The Firebrand Generator was installed inside the test section of the FRWTF at BRI. Figure 2a-b displays a layout of the facility. The facility was equipped with a $4.0 \mathrm{~m}$ fan to produce a wind field up to a $10 \mathrm{~m} / \mathrm{s}( \pm 10 \%)$. The wind velocity distribution was verified using a hot wire anemometer array. To track the evolution of the size and mass distribution of firebrands, a series of water pans was placed downstream of the Firebrand Generator. Depending on the structure to be tested, different assemblies were placed downstream of the Firebrand Generator (mock structures, roofing assemblies, etc.).

The Firebrand Generator was designed to produce firebrands characteristic to those produced from burning trees. Prior to designing the Firebrand Generator, Manzello et. al. [2021] conducted a series of experiments quantifying firebrand production from burning trees (see Figure 3). In that work, an array of pans filled with water was used to collect the firebrands that were generated from the burning trees. The firebrands were subsequently dried and the sizes were measured using calipers and the dry mass was determined using a precision balance. Based on the results of two different tree species of varying crown height and moisture content 
(Douglas-Fir Trees and Korean Pine Trees) burning singly under no wind, cylindrical firebrands were observed to be produced. Douglas-fir was selected as the tree species for the experiments in the USA since it is abundant in the Western United States of America and it is this part of the USA where WUI fires are most prevalent. Korean Pine, another conifer species, was used for comparison to Douglas-Fir. It was observed that more than $85 \%$ of the firebrands produced from these tree experiments were less than $0.4 \mathrm{~g}$ [20-21]. Therefore, the filtering procedure for tree mulch used in the Firebrand Generator was selected to produce firebrands with size/mass distributions commensurate to those measured from burning trees (see Figure 4).

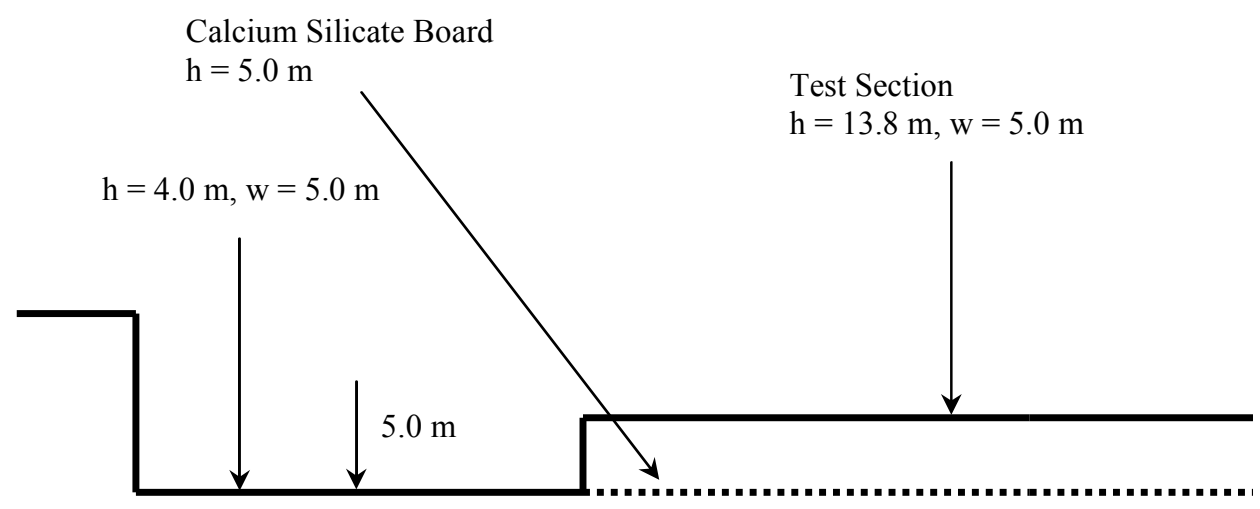

Flow Direction

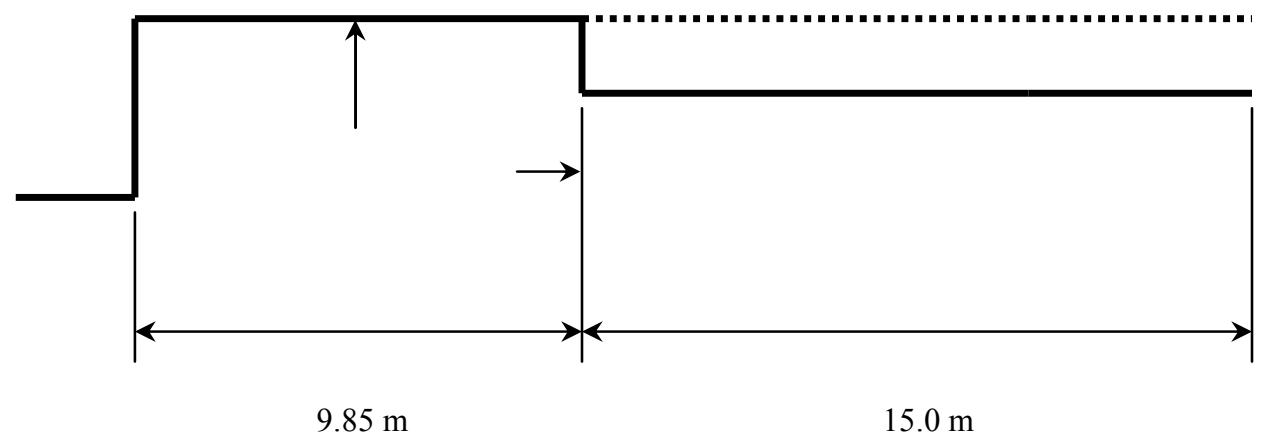

Figure 2a Schematic of test section of Fire Research Wind Tunnel Facility (FRWTF); h is height and $\mathrm{w}$ is width. 


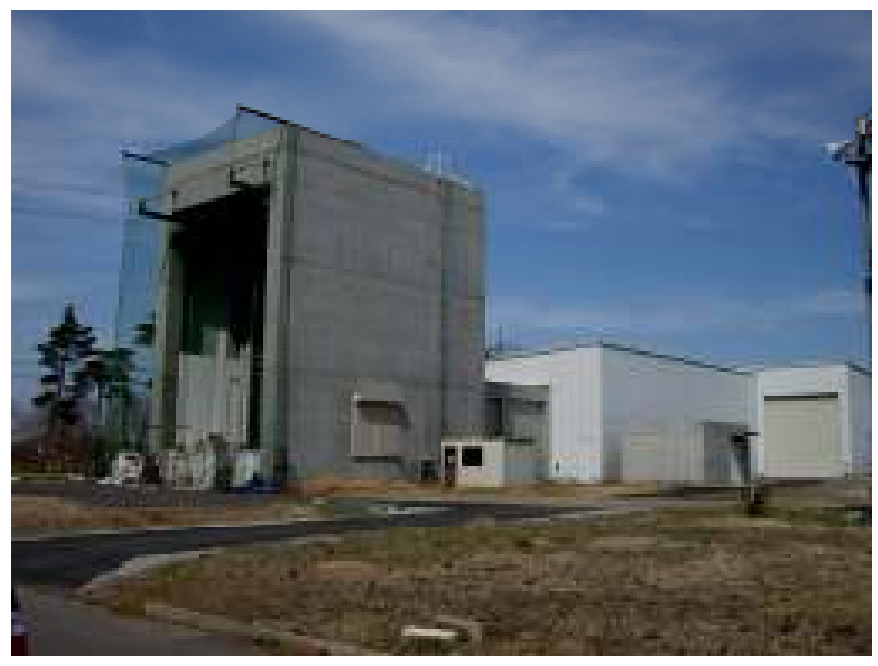

Figure 2b Photograph of FRWTF.

Firebrand size distribution produced using the NIST Dragon is also commensurate with the characteristics of firebrand exposure during a severe WUI fire in California (Angora Fire). The Angora fire burned 1,243 ha (3,072 ac) and approximately 353 buildings of all types [22]. Digital analyses of burn patterns from two different materials exposed to the Angora fire were conducted to determine firebrand size distributions. The firebrand size distributions determined from the Angora fire in collaboration with the California Department of Forestry and Fire Protection (CALFIRE), and are believed to be the first of such data from an actual WUI fire. Consistently small sizes of windblown firebrands, similar to those generated using the NIST Dragon, were observed by data collection from the Angora fire. This is in stark contrast with the size of firebrands referenced in existing test standards and wildfire protection building construction recommendations. Further details regarding the quantification of firebrand size distribution are provided elsewhere [22]. The danger of small wind driven firebrand showers is demonstrated in this report (see below).

The state of combustion of the firebrands generated using the NIST Dragon, namely glowing or flaming, is an important operational parameter that was considered when designing 
the device. It has been suggested that firebrands fall at or near their terminal settling velocity [6]. As such, when firebrands contact ignitable fuel beds, they are most likely in a state of glowing combustion, not open flaming. It is possible for firebrands to remain in a flaming state under an air flow and, it is reasonable to assume that some firebrands may still be in a state of flaming combustion upon impact. The purpose of the NIST Dragon is to simulate firebrand showers observed in long range spotting. Therefore, glowing firebrands were desired. Yet due to careful design of the NIST Dragon, it is also possible to generate flaming firebrand showers as well. All results presented here are for glowing firebrands.

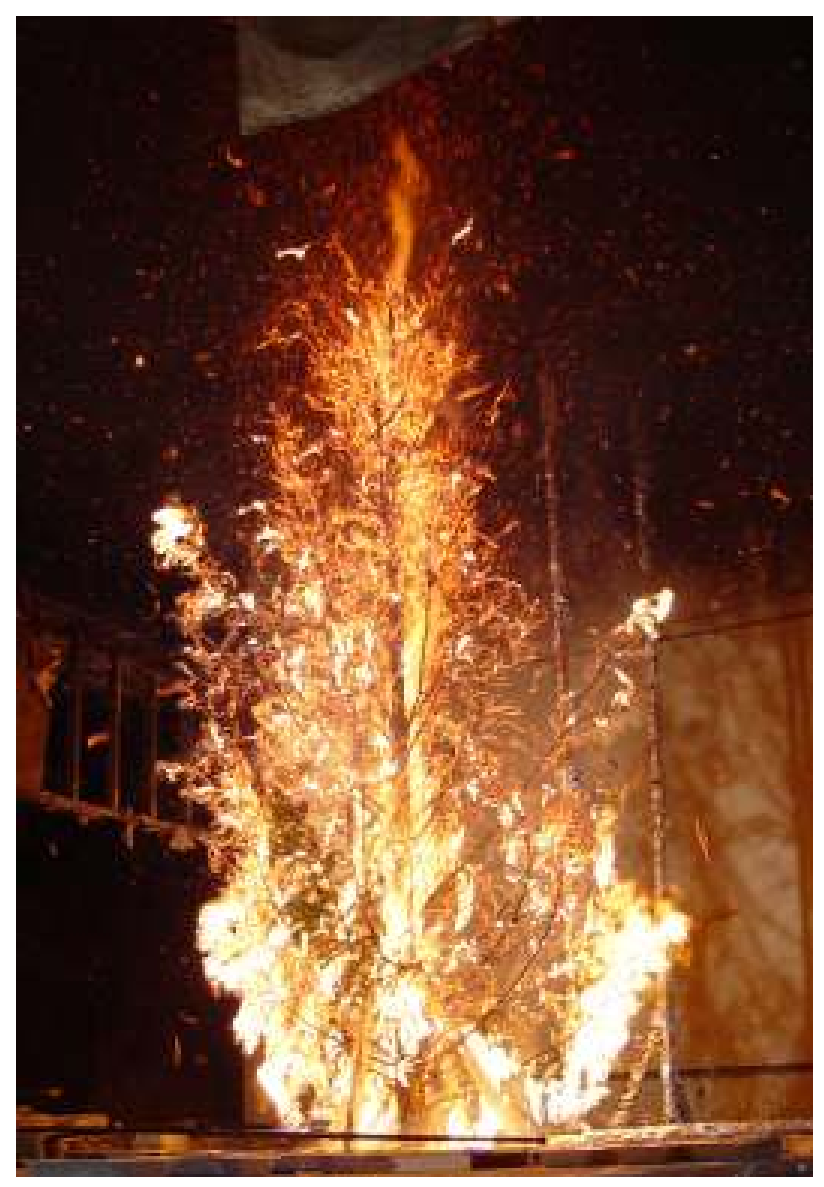

Figure 3 Photograph of a burning Douglas-Fir tree $(5.2 \mathrm{~m})$ used for firebrand collection. 


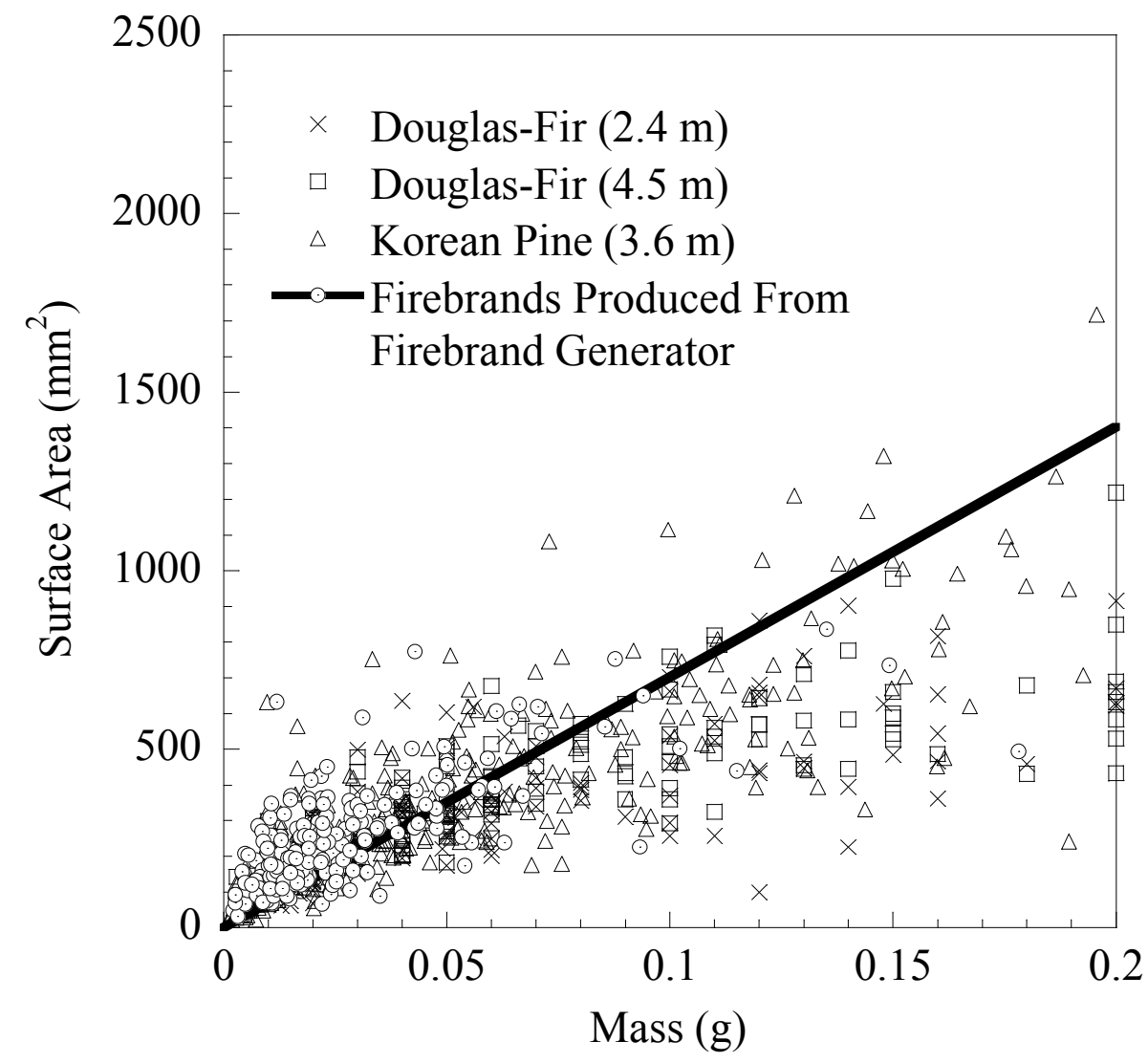

Figure 4 Firebrands produced from burning trees compared to those produced using the Firebrand Generator. The uncertainty in determining the surface area is $\pm 10 \%$.

\subsection{Roofing Vulnerabilities}

Post-fire studies have long identified a building ignition mechanism in which very small firebrands penetrate under a non-combustible tile roof covering to ignite a building [15-16]. Although current standards exist (e.g. ASTM E108 [23]) to test ignition of roofing decks to firebrands by placing a burning wood crib on top of a section of a roof assembly under an air flow, the dynamic process of multiple firebrands landing under ceramic tiles/gaps as a function 
of time is not taken into account. An experimental campaign was conducted to investigate the vulnerabilities of ceramic tile roofing assembles to ignition under a controlled firebrand attack using the NIST Firebrand Generator. A summary of these findings follows; further details regarding these experiments are provided elsewhere [17].

When new, ceramic tile roofing assemblies are constructed by placing a base layer of oriented strand board (OSB), then tar paper (TP) is installed on top of the OSB for moisture protection, and finally ceramic tiles (CT) are applied. Aged or weathered ceramic tile roofing assemblies were simulated by not installing tar paper. For simulated aged ceramic tile roof assemblies, without the installation of bird stops, the firebrands were observed to be blown under the ceramic tiles (see Figure 5). Bird stops, as the name suggests, are intended to mitigate the construction of nests by birds under the ceramic tiles. During the experiments, eventually, several firebrands would collect and would produce smoldering ignition (SI) within the OSB base layer. With continued application of the airflow, holes were formed within the OSB and eventually the SI would transition to flaming ignition (FI). Simulated aged ceramic tile roof assemblies, with bird stops installed, were also constructed for testing. Even though bird stops were installed, many firebrands were able to penetrate the gaps that exist between the ceramic tiles and the bird stops. These firebrands were observed to produce SI within the OSB base layer; holes were observed in some cases within the OSB base layer. The SI ignition never transitioned to FI when bird stops were applied.

The use of tar paper was then used to simulate a newly constructed ceramic tile roof assembly. With the application of tar paper, experiments were conducted first without bird stops installed. Once again, firebrands were blown under the ceramic tiles. The firebrands were able to burn several holes within the tar paper and produced SI within the OSB base layer. The SI 
was not intense enough to result in the production of holes within the OSB base layer. Tests were then conducted that considered the application of tar paper with bird stops installed. These conditions resulted in no ignition in the tar paper and thus no ignition within the OSB layer.
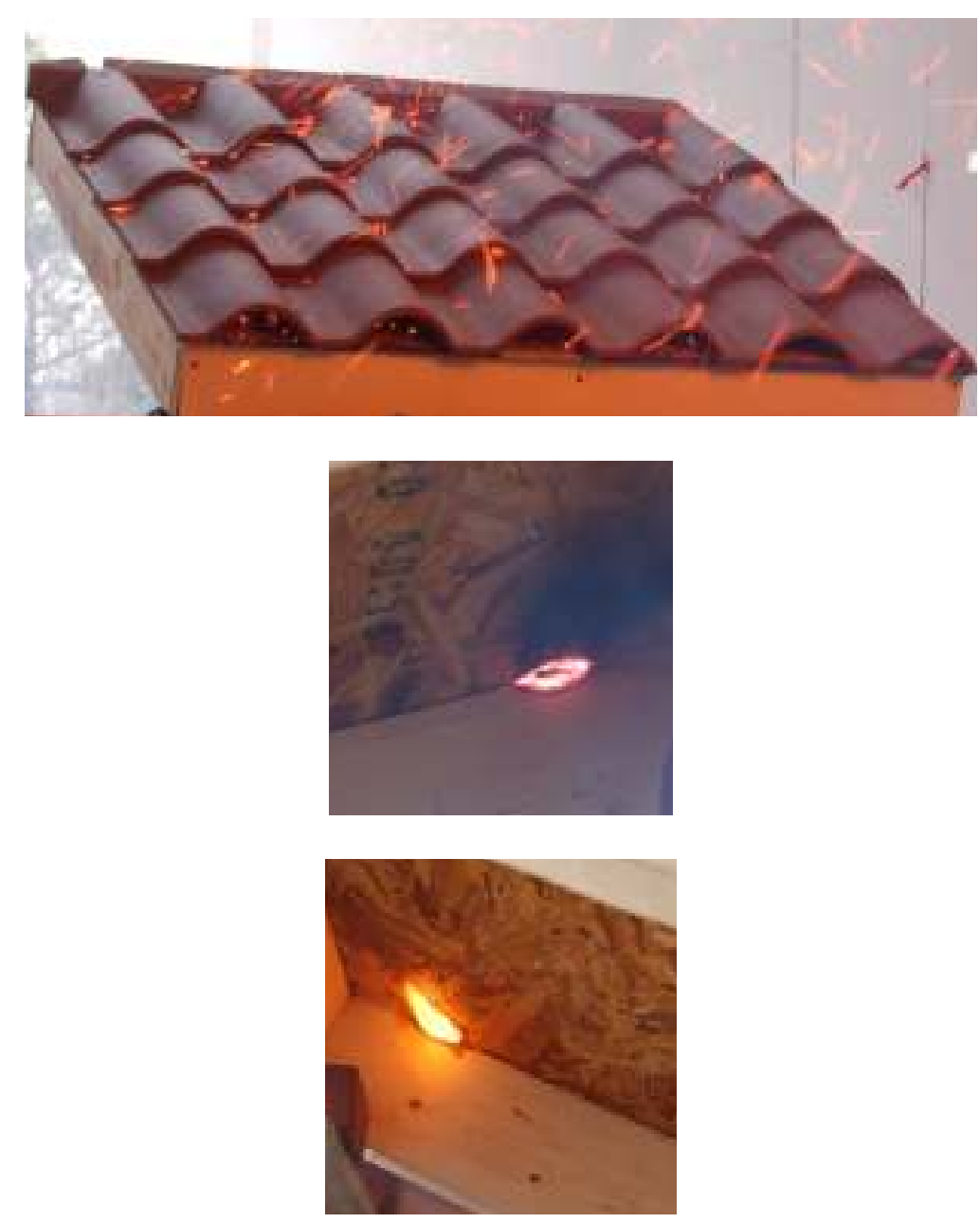

Figure 5 Images of experiments conducted using OSB/CT without bird stops installed. Intense SI was observed within the OSB base layer and eventually FI was observed. The wind tunnel speed was $7 \mathrm{~m} / \mathrm{s}$ and the Firebrand Generator was located $2.0 \mathrm{~m}$ from the CT roofing assembly.

The influence of dried pine needles and leaves accumulating under the ceramic tiles was subsequently considered. Even when bird stops were installed, as ceramic tile roof assemblies were exposed to the elements over time, the deposition of dead needles and leaves under the tiles would be expected. The result, summarized above, namely that the combination of the bird stop installation coupled with the tar paper application provided a barrier to ignition, does not hold 
true if dead needles and leaves were placed under the tiles. If needles and leaves are deposited under the tiles, ceramic tile roofing assemblies are ignitable under all conditions considered in this study.

All of the experiments summarized above considered perfectly aligned roofing tiles that would be expected in new roof construction. As ceramic tile roof assemblies age, the tile alignment does not remain so closely spaced. In fact, large gaps develop within the tiles themselves leading to openings where firebrands may enter and accumulate. To quantify this vulnerability, a final series of experiments were conducted where the ceramic tiles were not fit together perfectly. The types of gaps simulated were based on surveys of actual roofs. Due to the presence of gaps within the tiles, ignition under the tiles within the OSB base layer was observed: (1) whether or not bird stops were installed, (2) whether or not tar paper was installed. This result is somewhat obvious and suggests that when gaps exist within the alignment of the ceramic tiles, ignition of the assembly is rather easy. The application of dead needles and leaves was not even considered with gaps present in the ceramic tiles as this would only compound the vulnerabilities to ignition. These results are the first ever experiments to ascertain the vulnerabilities of ceramic tile roofing assemblies.

In addition to investigating ceramic tile roofing assemblies, full-scale sections of asphalt shingle roofing assemblies were constructed and exposed to firebrand showers; a summary of these results follows with more details available in Manzello et al. [16]. Both flat roof sections as well as angled (valleys) were considered. The full-scale sections constructed for testing included asphalt shingle roofing assemblies (OSB, tar paper, and asphalt shingles) as well as only base layer roofing materials, such as OSB. It is important to realize that bare OSB is not 
used as the surface material in roofing but roofs in a state of ill repair may easily have base layer materials such as OSB exposed to firebrand showers.

For ignition testing of roofing base layer materials (OSB), at an angle of $60^{\circ}$, the firebrands were observed to collect inside the channel of the OSB crevice (see Figure 6a-c). The firebrands that collected in the crevice produced SI where they landed, eventually resulting in several holes in the OSB. The OSB continued to smolder intensely near the locations where the firebrands landed. Eventually a transition to FI was observed on the back side of the OSB. As the angle was increased to $90^{\circ}$, similar behavior was observed where the firebrands that collected initiated intense smoldering. Eventually, holes were formed at these locations in an identical manner to the $60^{\circ}$. While SI was observed, it was not possible for a transition to flaming to occur. As the angle was increased to $135^{\circ}$, ignition was no longer possible.

With regard to ignition testing of roofing valleys (OSB, tar paper, and asphalt shingles), at $60^{\circ}$ and $90^{\circ}$, several firebrands were observed to become trapped along the channel of two sections and along the seams of the shingles. However, no ignition events were observed. The firebrands were only capable of melting the asphalt shingles (see Figure 7). As the angle was spread further, fewer firebrands were observed to become trapped in the seam of the two sections, in a similar manner to the base layer OSB tests. While these tests did not consider the influence of aged or pre-heated shingles, the results clearly indicate that firebrands can melt asphalt shingles.

Pine needles in the gutters of homes may be susceptible to ignition by firebrand showers. To investigate this, a flat roof section was built and a gutter was attached to the front. The gutter was constructed of polyvinyl chloride (PVC); a gutter material found in new home construction. As in the roof valley experiments described above, OSB was used as the base layer; tar paper and 
shingles were then applied. Dried pine needles and leaves were used and placed inside the gutter.
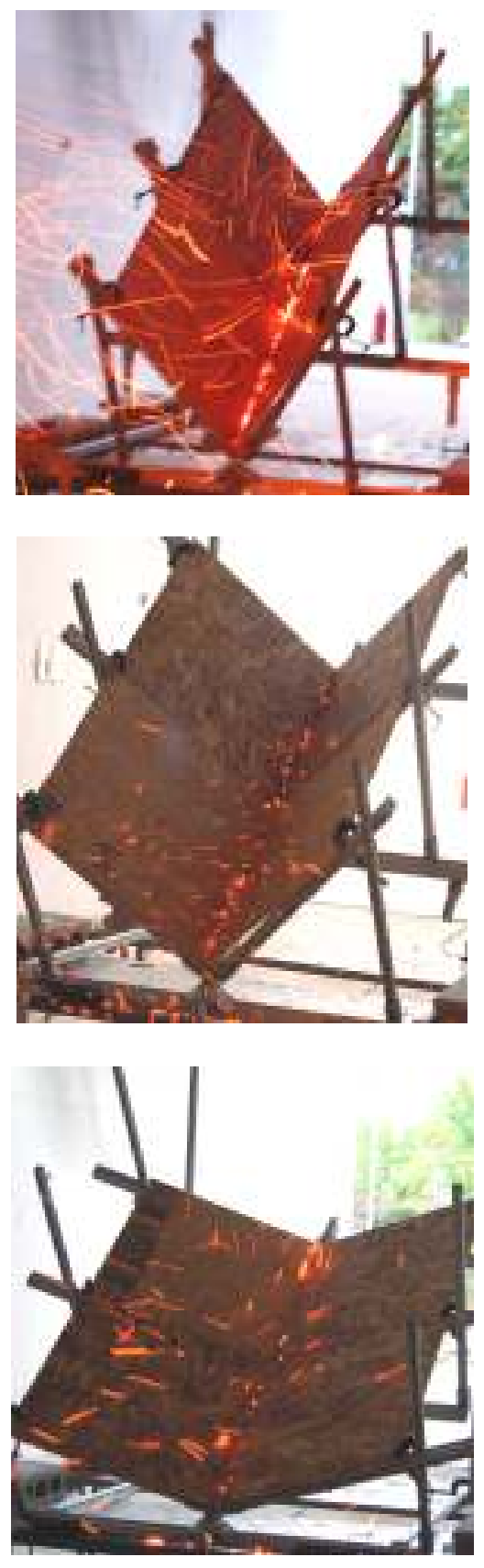

Figure 6 Bare OSB full-scale sections used for testing. (a) Angle of $60^{\circ}$; smoldering ignition observed (b) Angle of $90^{\circ}$; smoldering ignition observed (c) Angle of $135^{\circ}$; no ignition observed. The wind tunnel speed was $7 \mathrm{~m} / \mathrm{s}$ in each case. 
Figure 8a-b displays typical results obtained from the experiments. The firebrands that were deposited inside the gutter produced SI inside the gutter. The smoldering intensified and ultimately this transitioned to FI. The asphalt shingles were observed to melt once exposed to the intense flaming that occurred inside the gutter. The flames, however, did not spread up the roof section. While the flames did not spread upwards along the roof, these images are very important since they clearly show the dangers of not cleaning gutters. The influence of preheated shingles as well as aged shingles was not addressed.

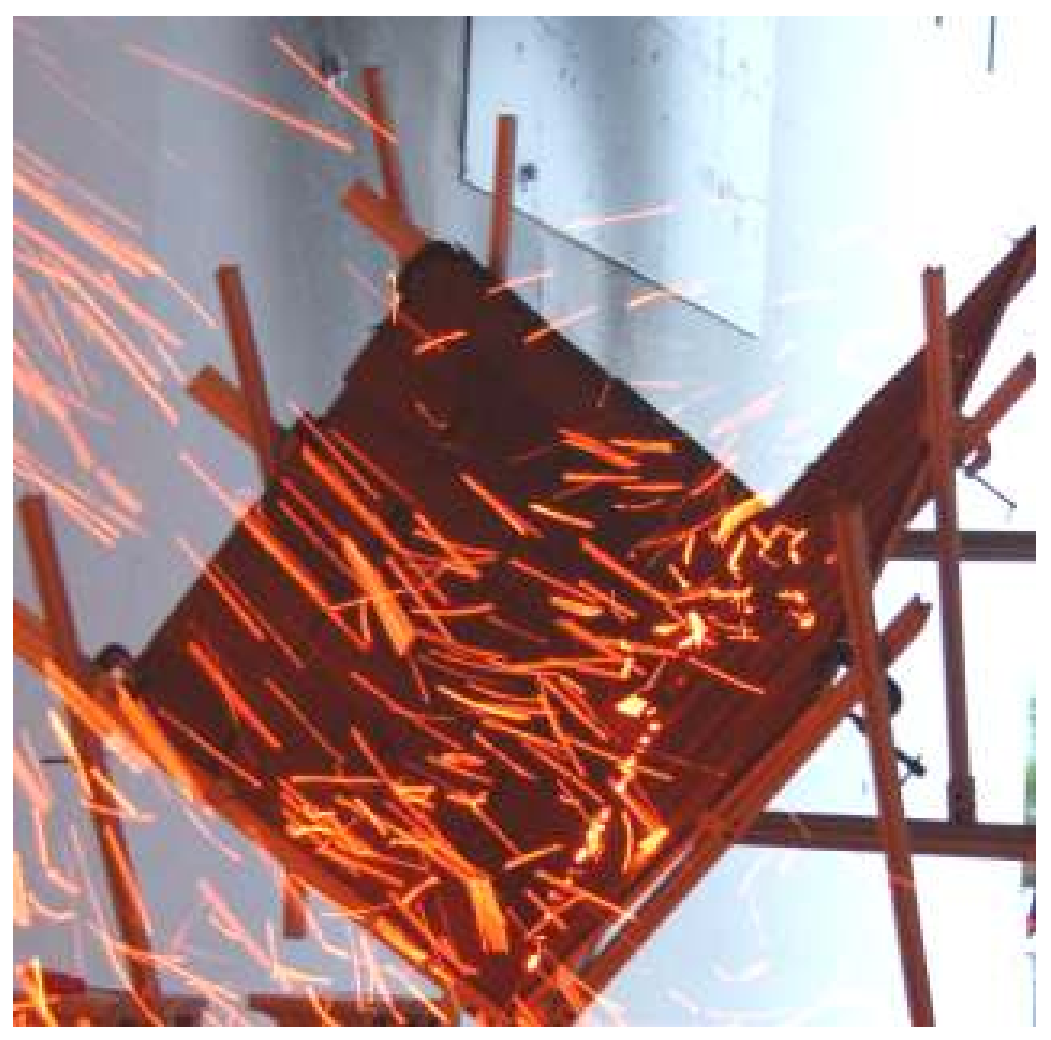

Figure 7 OSB base layer, tar paper, and asphalt shingles; Angle of $90^{\circ}$-no ignition observed. The wind tunnel speed was $7 \mathrm{~m} / \mathrm{s}$. 


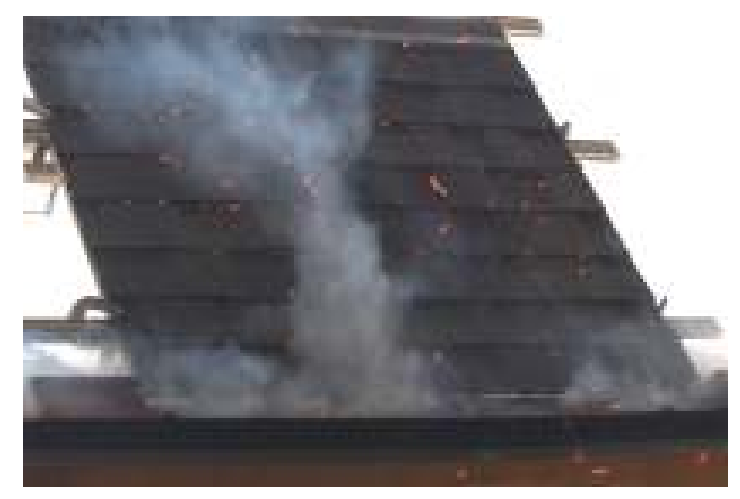

(a)

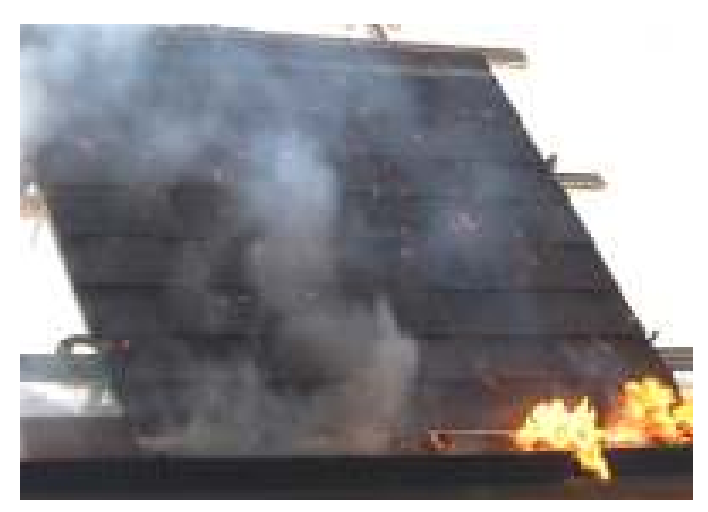

(b)

Figure 8 Section of full-scale roof assembly. (a) Smoldering ignition of needles/leaves inside gutter (b) Transition to flaming ignition. The wind tunnel speed was $7 \mathrm{~m} / \mathrm{s}$.

\subsection{Building Vent Vulnerabilities}

The 2007 California Building Code of Regulations, Title 24, Part 2, Chapter 7A, desired to mitigate firebrand penetration through building vents by recommending a metal mesh of $6 \mathrm{~mm}$ be placed behind building vents [24]. Yet, this mesh size was not based on any scientific testing since no test methods were available at that time. Therefore, the Firebrand Generator was used to study the penetration of firebrands into building vents [15]. In that work, firebrand penetration into a gable vent fitted with a mesh assembly (only three mesh sizes were used - $6.0 \mathrm{~mm}, 3.0$ $\mathrm{mm}$, and $1.5 \mathrm{~mm}$ opening) was investigated and shredded paper was placed behind the mesh to determine if firebrands that penetrated the vent and subsequent mesh were able to produce an 
ignition event [15]. That study showed that firebrands were not quenched by the presence of the mesh and would continue to burn on the mesh until they were small enough to pass through the mesh opening. For the $6 \mathrm{~mm}$ mesh, a majority of the firebrands simply flew through the mesh, resulting in more rapid ignition of flammable materials behind the mesh than that observed for the smaller mesh sizes of $3 \mathrm{~mm}$ and $1.5 \mathrm{~mm}$.

Recently, a more in depth investigation aimed at extensively quantifying firebrand penetration through building vents using full-scale tests at BRI was completed in collaboration with ASTM (details below). Namely, six different mesh sizes were considered, from $5.72 \mathrm{~mm}$ to $1.04 \mathrm{~mm}$ opening, as well as four different types of ignitable materials placed inside the structure. This greater range of parameters allowed for the generation of a database of firebrand penetration behavior and subsequent ignition of materials placed behind varying mesh sizes. A more summary of these findings is provided elsewhere [18]; a terse summary is provided here.

The overall dimensions of the target structure, placed $7.5 \mathrm{~m}$ downstream of the NIST Dragon, were $3.06 \mathrm{~m}$ in height, $3.04 \mathrm{~m}$ in width, and $3.05 \mathrm{~m}$ in depth. The structure was constructed of calcium silicate (non-combustible) board. A generic building vent design, consisting of only a frame fitted with a metal mesh, was used. The vent opening was fitted with six different types of metal mesh: 4 x 4 mesh $\times 0.65 \mathrm{~mm}$ wire diameter, $8 \times 8$ mesh $\times 0.43 \mathrm{~mm}$ wire diameter, $10 \times 10$ mesh $\times 0.51 \mathrm{~mm}$ wire diameter, $14 \times 14$ mesh x $0.23 \mathrm{~mm}$ wire diameter, $16 \times 16$ mesh $\times 0.23 \mathrm{~mm}$ wire diameter, and $20 \times 20$ mesh $\times 0.23 \mathrm{~mm}$ wire diameter. These mesh sizes corresponded to opening sizes of: $5.72 \mathrm{~mm}(4 \times 4), 2.74 \mathrm{~mm}(8 \times 8), 2.0 \mathrm{~mm}(10 \mathrm{x}$ 10), $1.55 \mathrm{~mm}(14 \times 14), 1.35 \mathrm{~mm}(16 \times 16)$, and $1.04 \mathrm{~mm}(20 \times 20)$. Mesh was defined, per the manufacturer, as the number of openings per $25.4 \mathrm{~mm}$ (1"). 
For building ventilation, common vents include gable vents, foundation vents, and eave or soffit vents. Gable vents and eave vents are used for attic ventilation and foundation vents are used to provide air flow to crawl space areas. Prior to conducting the experiments, computer simulations were conducted using the NIST Fire Dynamics Simulator (FDS) to visualize the flow around the structure in the FRWTF [25]. FDS is a computational fluid dynamics model of fire-driven fluid flow and numerically solves a form of the Navier-Stokes equations appropriate for low-speed, thermally driven flow. While FDS was designed with fire in mind, it may be used, as in the case of the simulations conducted in this study, for low-speed fluid flow simulations that do not involve fire [25]. The results of the simulations are presented in Figure 9a-b. As mentioned, the flow profile inside the FRWTF was mapped out using a series of hot wire anemometers (21 point array). Based on these measurements, the flow profile was observed to be uniform. As a result, in these simulations, the flow profile inside FRWTF was assumed uniform and fixed at $7 \mathrm{~m} / \mathrm{s}$.

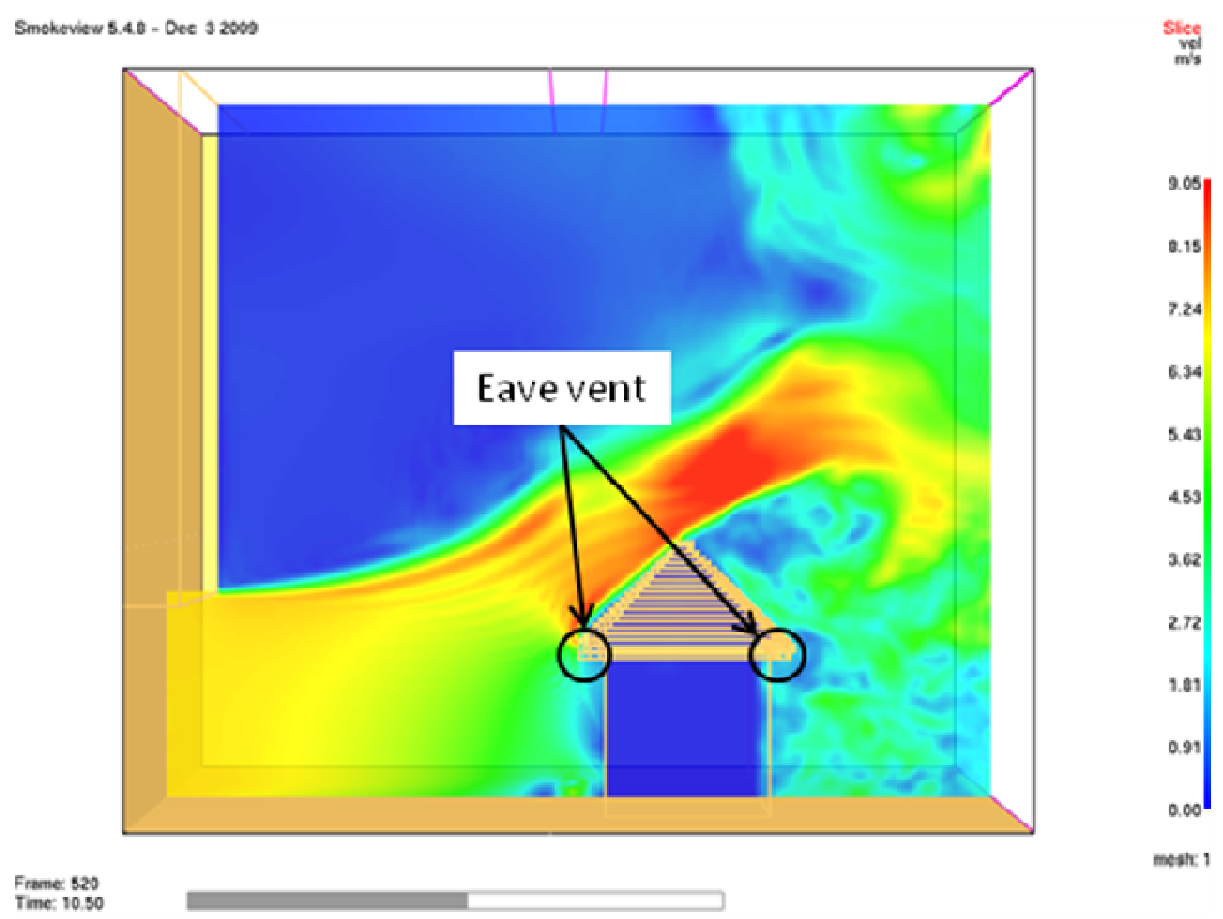

Figure 9 (a) House with eave vents. 

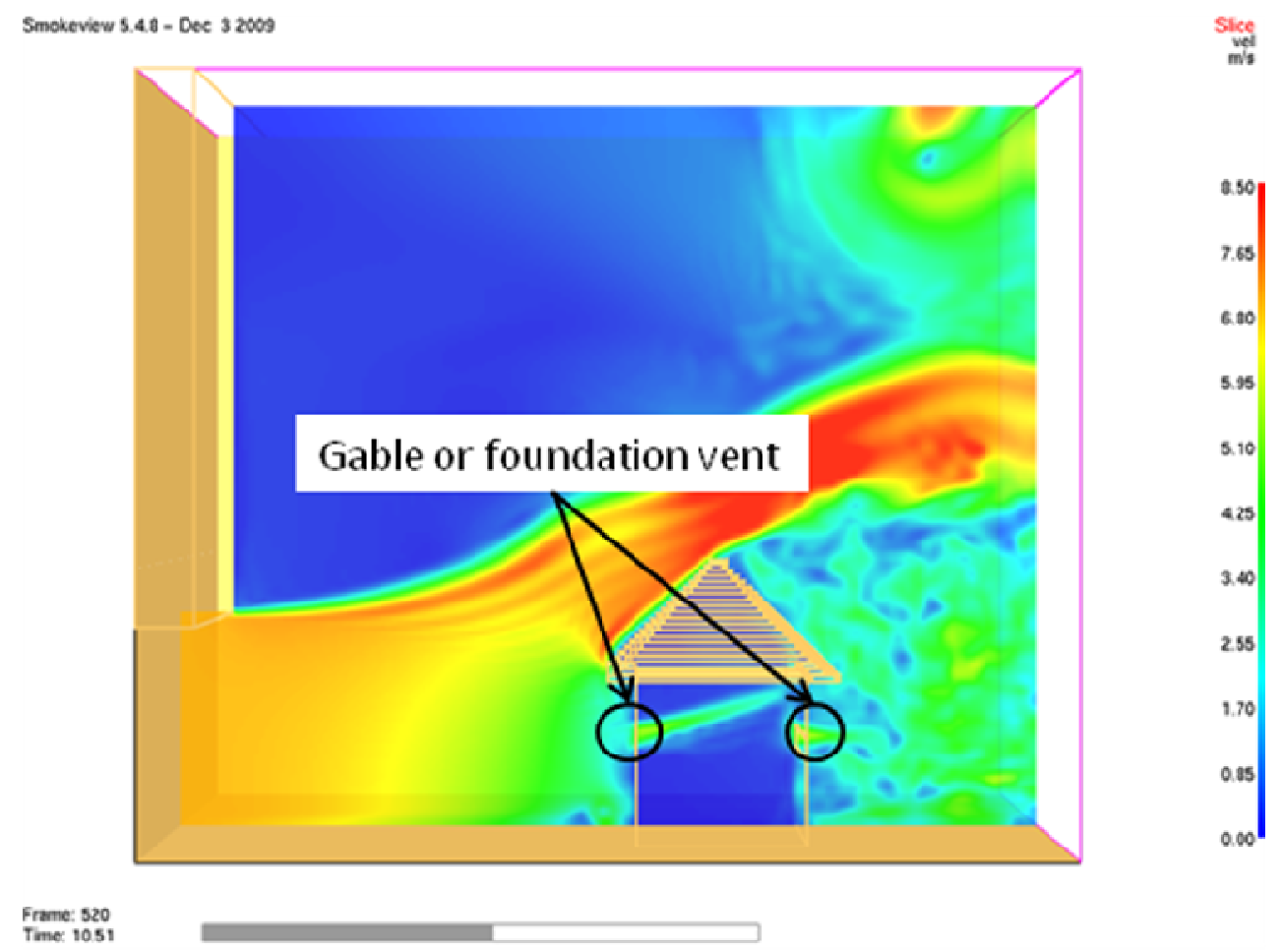

Figure 9 (b) House with gable or foundation vents.

Since eave vents, as the name suggests, are placed horizontally under an eave, simulations were performed to compare air flow profiles of a vent placed under an eave as compared to a vent placed vertically, such as a foundation or gable vent (see Figure 9a-b). In each simulation, the size of the vent opening was the same $(40 \mathrm{~cm}$ by $20 \mathrm{~cm})$. Specifically, one $40 \mathrm{~cm}$ by $20 \mathrm{~cm}$ opening was placed under each eave (Figure 9a-b). For the simulations that considered a vent placed vertically, one $40 \mathrm{~cm}$ by $20 \mathrm{~cm}$ opening was placed on the front and back face of the structure. Clearly, for a vent placed under an eave, the simulations demonstrate that a great deal of flow recirculation exists, implying less likelihood for firebrands to actually arrive at such a location. On the other hand, for a vent placed vertically and not under an eave, it is far easier for air flow to arrive less perturbed at this location. For completeness, in these simulations, the computational domain was the same as the BRI FTWTF (Figure 2a), the grid 
size used was $5 \mathrm{~cm}$, and the structure dimension was the same as the one used in the experiments (Figure 4). As a result, the placement of the mesh assembly, on the front face of the structure, was intentionally selected to provide an intense flux of firebrands from the NIST Firebrand Generator. It also allowed comparison to prior BRI/NIST work that considered a gable vent fitted with a mesh assembly [18].

Behind the mesh, four different materials (all materials were oven dried) were placed to ascertain whether the firebrands that were able to penetrate the building mesh assembly could ignite these materials. The materials were shredded paper, cotton, crevices constructed with OSB and wood (to form $90^{\circ}$ angle). For the crevice tests, experiments were conducted with the crevice filled with or without shredded paper. The purpose of using the crevice was to determine if firebrands that penetrated the mesh were able to ignite building materials. Paper in the crevice was intended to simulate fine fuel debris.

For the full-scale tests, the wind tunnel speed was fixed at $7 \mathrm{~m} / \mathrm{s}$. The velocity behind the mesh varied from $7 \mathrm{~m} / \mathrm{s}(4 \times 4$ mesh; $5.72 \mathrm{~mm}$ opening) to $5 \mathrm{~m} / \mathrm{s}(20 \times 20$ mesh; $1.04 \mathrm{~mm}$ opening). Three repeat experiments were conducted for each of the four ignitable materials considered and the results are tabulated in Table 1. The acronyms in the table are as follows: NI - no ignition; SI - smoldering ignition; FI - flaming ignition. Figure 10 displays a picture of a typical experiment. In this particular experiment, the mesh used was $20 \times 20(1.04 \mathrm{~mm})$.

An important factor to consider for the full scale tests was that while the Firebrand Generator produced a large number of firebrands, all of these firebrands do not actually arrive at the mesh location due to flow recirculation produced by the presence of the structure. To quantify the distribution of firebrands arriving at the mesh area as a function of time, experiments were conducted using the $20 \times 20(1.04 \mathrm{~mm})$ mesh, since this mesh size initially 
trapped all firebrands on it prior to their continuous burning and ultimate penetration through the mesh. This allowed for the ability to simply count the time varying number of firebrands arriving at the given mesh area.

To accomplish this in an efficient manner, image analysis was performed. To distinguish glowing firebrands from the uneven background required correcting the uneven illumination across the images by offsetting the background and then a $3 \times 3$ average spatial filter was applied to reduce the image noise. To further aid image processing, the images were converted into an 8-bit image. A binary image (that only consists of black and white pixels) was then produced from the 8 bit image by setting a fixed threshold value for the identification of glowing firebrands. All white pixels belonging to a same body was finally grouped as one firebrand in order to count the firebrand. The data obtained from this analysis is shown in Figure 11.

When shredded paper was used, a repeatable SI was observed for all mesh sizes up to 16 x $16(1.35 \mathrm{~mm})$. As for the smallest mesh size tested $(20 \mathrm{x} 20)(1.04 \mathrm{~mm})$, SI was observed in only one experiment out of three. For cotton, the ignition behavior was similar for all mesh sizes. The firebrands would deposit into the cotton bed and simply burn holes into the cotton.

The bare wood crevice experiments resulted in SI in the OSB layer for the $4 \times 4(5.72$ $\mathrm{mm})$ and $8 \times 8(2.74 \mathrm{~mm})$ mesh sizes. As the mesh size was reduced to $10 \times 10(2.0 \mathrm{~mm})$, the firebrands were not able to ignite the bare wood crevices. When the crevices were filled with shredded paper, SI followed by FI occurred in the paper for mesh sizes up $10 \times 10(2.0 \mathrm{~mm})$. The OSB layer was then observed to ignite by SI and subsequently produced a self-sustaining SI that continued to burn holes into the OSB. For the smallest mesh sizes tested (16 x 16 and $20 \mathrm{x}$ 20), NI was observed in the paper and consequently NI in the crevice. The results of an experiment conducted using 10 x $10(2.0 \mathrm{~mm})$ mesh are shown in Figure 12. 
Similar to prior BRI/NIST experiments that used a gable vent fitted with a mesh $(6.0 \mathrm{~mm}$, $3.0 \mathrm{~mm}$, and $1.5 \mathrm{~mm}$ ) [18], firebrands were not quenched by the presence of the mesh and would continue to burn until they were able to fit through the mesh opening. In the present work, the same behavior was observed for the smaller mesh sizes used (16 x 16, $1.35 \mathrm{~mm} ; 20 \times 20,1.04$ $\mathrm{mm})$.

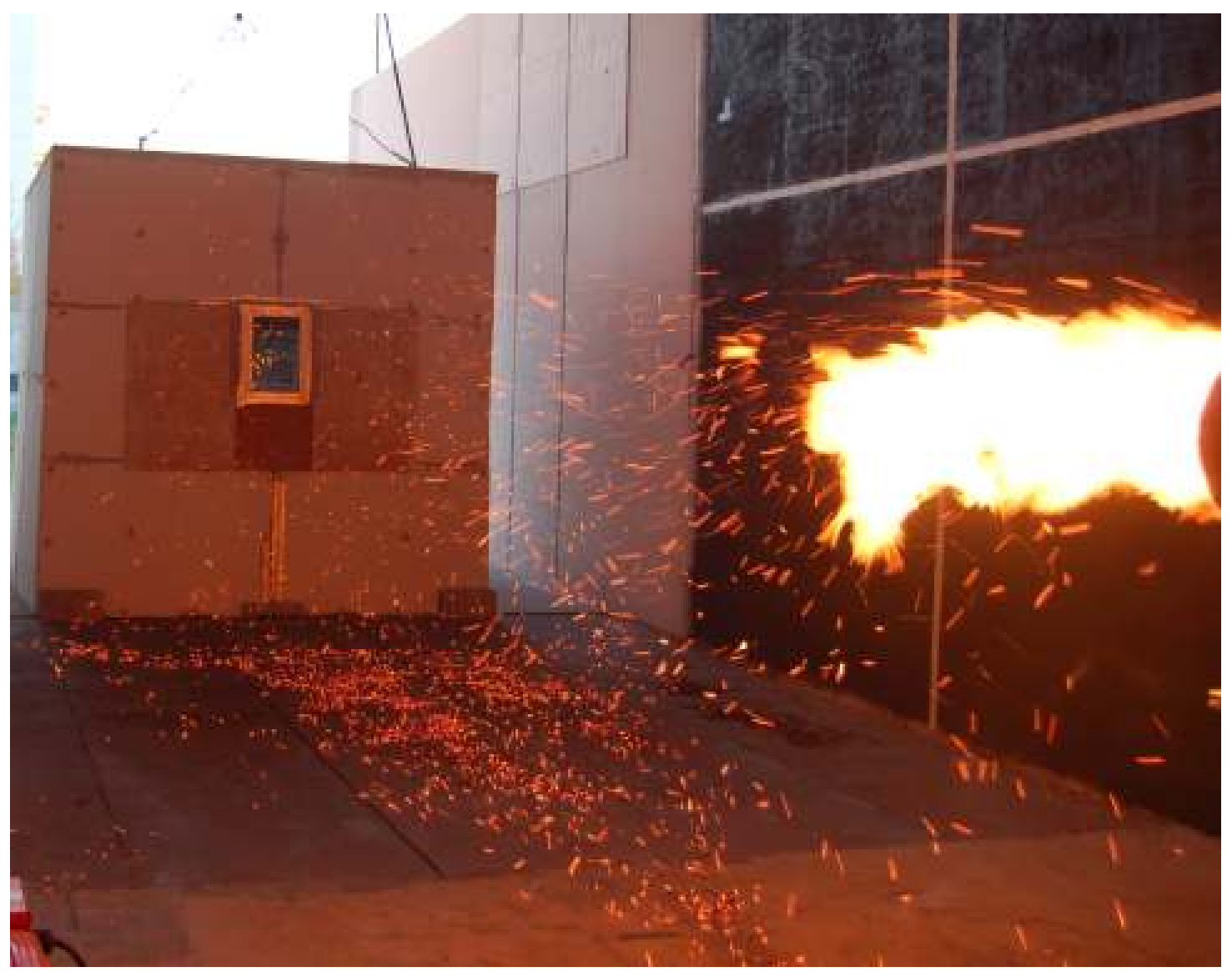

Figure 10 Typical experiment using NIST Firebrand Generator at BRI's FRWTF. The mesh installed in this experiment was $20 \times 20(1.04 \mathrm{~mm})$, the wind tunnel speed was $7 \mathrm{~m} / \mathrm{s}$, and the Firebrand Generator was located $7.5 \mathrm{~m}$ from the structure. 


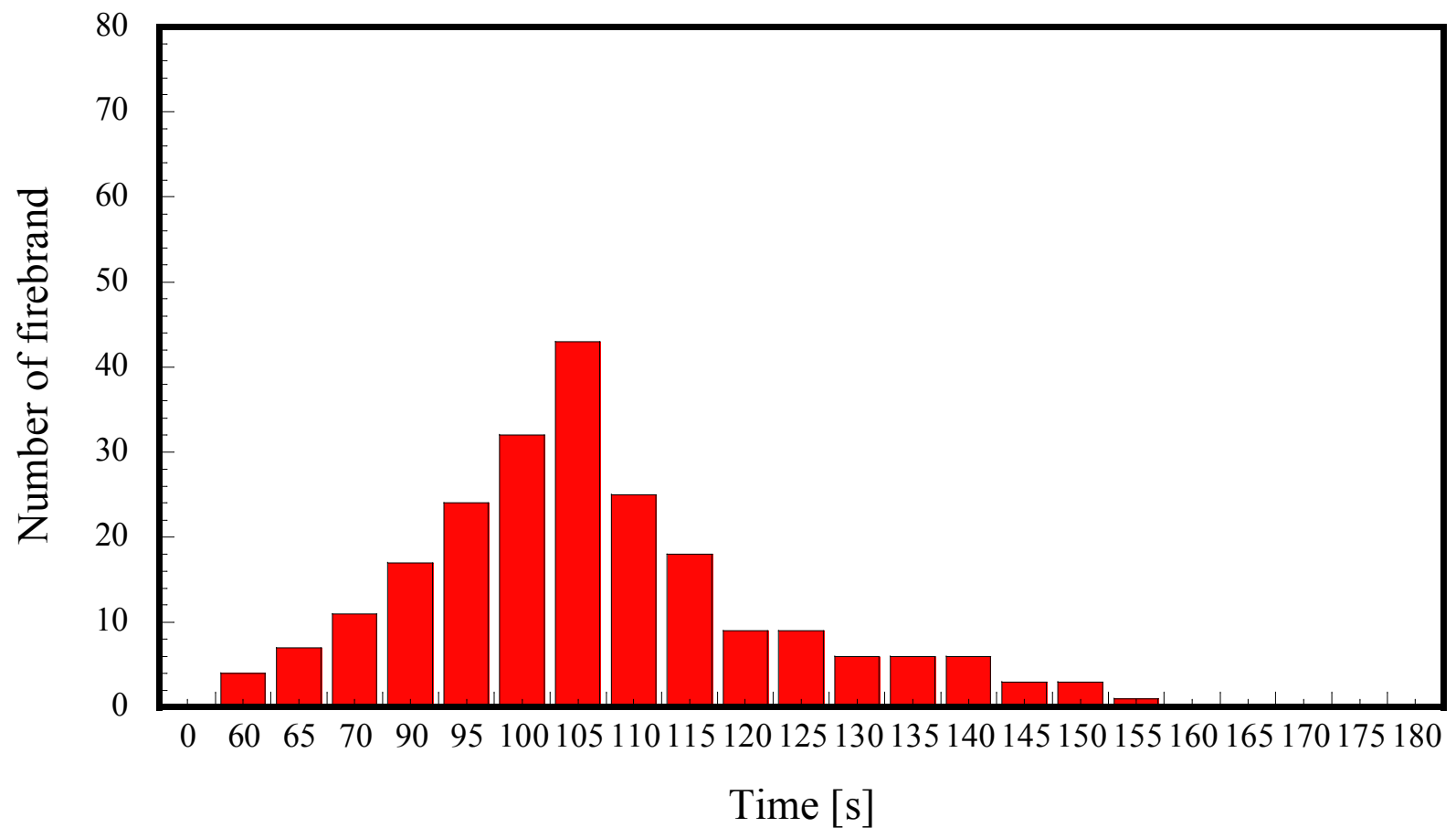

Figure 11 Number of firebrands arriving on the mesh as a function of time for the full scale experiments. The mesh area was $1600 \mathrm{~cm}^{2}$. At each time, the number of firebrands plotted in the figure was based on the average of three repeat experiments. The relative variation in the average number of firebrands measured was similar for all times (less than $20 \%$ ).

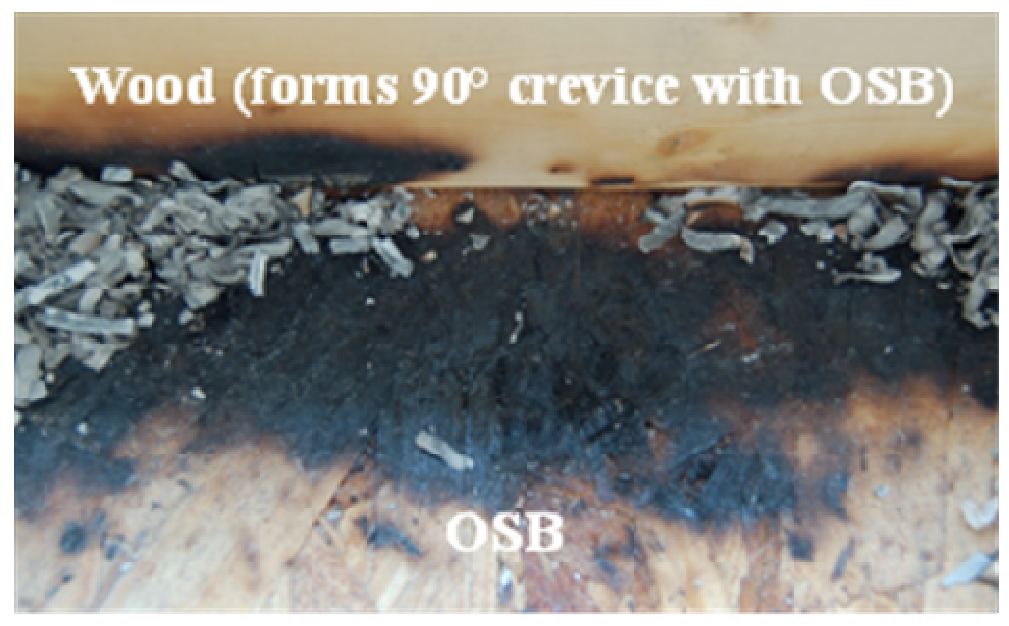

Figure 12 Images obtained (top view) for crevice filled with paper tests using 10 x $10(2.0 \mathrm{~mm})$ mesh. 
Table 1 Summary of full-scale tests at BRI. 72 experiments were conducted.

\begin{tabular}{|c|c|c|c|c|}
\hline Mesh & Paper & Cotton & Crevice & $\begin{array}{l}\text { Crevice with } \\
\text { paper }\end{array}$ \\
\hline $\begin{array}{c}4 \times 4 \\
(5.72 \mathrm{~mm})\end{array}$ & SI to FI & SI & SI & $\begin{array}{l}\text { SI to FI (paper) } \\
\text { SI (OSB) }\end{array}$ \\
\hline $\begin{array}{c}8 \times 8 \\
(2.74 \mathrm{~mm})\end{array}$ & SI to FI & SI & SI & $\begin{array}{l}\text { SI to FI (paper) } \\
\text { SI (OSB) }\end{array}$ \\
\hline $\begin{array}{c}10 \times 10 \\
(2.0 \mathrm{~mm})\end{array}$ & SI to FI & SI & NI & $\begin{array}{l}\text { SI to FI (paper) } \\
\text { (SI OSB) }\end{array}$ \\
\hline $\begin{array}{c}14 \times 14 \\
(1.55 \mathrm{~mm})\end{array}$ & SI & SI & NI & $\begin{array}{l}\text { SI (paper) } \\
\text { SI (OSB) }\end{array}$ \\
\hline $\begin{array}{c}16 \times 16 \\
(1.35 \mathrm{~mm})\end{array}$ & SI & SI & NI & $\mathrm{NI}$ \\
\hline $\begin{array}{c}20 \times 20 \\
(1.04 \mathrm{~mm})\end{array}$ & $\begin{array}{l}\text { Two tests: NI; } \\
\text { One test SI }\end{array}$ & $\begin{array}{l}\text { Two tests: SI } \\
\text { One Test NI }\end{array}$ & NI & NI \\
\hline
\end{tabular}

NI - no ignition; SI - smoldering ignition; FI - flaming ignition.

In summary, these experiments found that firebrands were not quenched by the presence of the mesh and would continue to burn until they were able to fit through the mesh opening, even down to a $1.04 \mathrm{~mm}$ opening (shown in Figure 13). Mesh size reduction did mitigate ignition of bare wood crevices. Yet, ignition of fine fuel was still observed as mesh size was reduced suggesting that firebrand resistant vent technologies would be helpful.

During the 2010 triennial code change cycle in California, no standard test methods were available to evaluate and compare firebrand resistant vent technologies. Therefore, NIST worked with the California Department of Forestry and Fire Protection (CALFIRE) as part of a task force in order to reduce mesh size used to cover building vent openings to lessen the potential hazard of firebrand entry into structures. These changes were formally adopted into the 
2010 California Code of Regulations, Title 24, Part 2, Chapter 7A, and are effective January, $2011[26]$.

(a) Front vicw

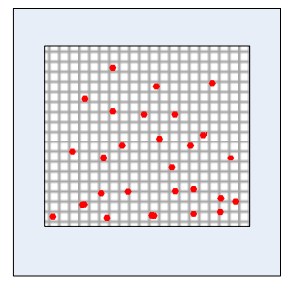

(b) Side vicw
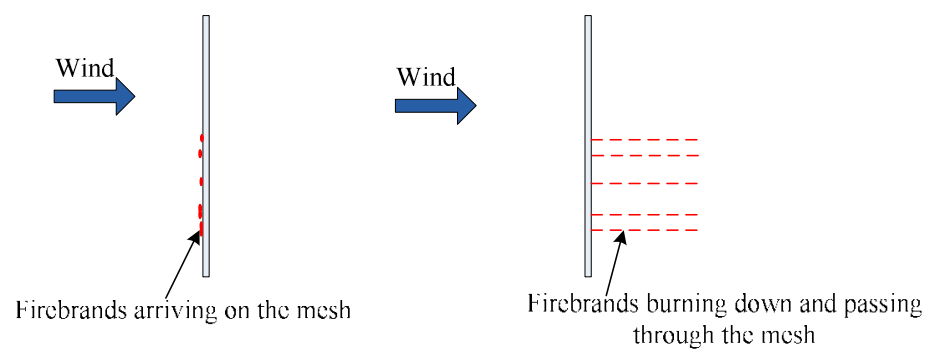

Figure 13 Schematic of firebrand penetration through a mesh.

An ASTM task group on vents, organized within Subcommittee E05.14.06, External Fire Exposures, has been working to develop a reduced-scale test method (not presently a standard) aimed at evaluating the ability of vents to resist firebrand intrusion into attic and crawl space areas. In this test method, firebrands are produced by igniting wood pieces and the firebrands are subsequently deposited on top of the vent installed in the test chamber. The vent is placed horizontally in the apparatus and air is pulled through the vent using a fan placed downstream. The mechanism of firebrands residing on top of vents and being pulled down onto vents is not representative of the actual situation. Firebrands are actually blown onto the vents themselves.

Therefore, a comparison testing protocol was undertaken, with the formal support [27] of the ASTM E05.14.06 task group, between the method developed by ASTM to the full-scale experiments using the NIST Firebrand Generator at BRI's FRWTF as these full-scale tests 
developed by BRI/NIST attempt to simulate a wind driven firebrand attack that is seen in actual WUI fires. This comparison testing protocol was undertaken to determine if the reduced-scale method (ASTM) was able to effectively represent firebrand penetration through building vents observed using the full-scale test method. The results of the comparison testing protocol are beyond the scope of this paper, are the subject of a future publication, and have been balloted as part of an ASTM standard.

\subsection{Siding Treatment Vulnerabilities}

Anecdotal evidence exists related to vulnerabilities of siding treatments, walls fitted with eaves, and glazing assemblies to firebrand attack, yet standard test methods are not available to evaluate the ability of these construction elements to resist firebrand showers. Before the development of the NIST Firebrand Generator and the subsequent coupling of this device to the FRWTF, there was no method to actually generate firebrand showers in a controlled, laboratory setting to quantify these vulnerabilities. Therefore, a workshop was held in June, 2010 by NIST to provide input on the type of siding treatments, eaves assemblies, and glazing assemblies most common and important to consider for experimentation [28]. The focus has been placed on the state of California since many large WUI fires have occurred there over the past 10 years [28].

Siding treatments applied in a re-entrant corner configuration are believed to be the most vulnerable to firebrand showers, since firebrands may become trapped not only under the siding itself but also within the corner post (see Figure 14a; corner posts commonly used for vinyl and polypropylene siding). For cedar shingle siding, it is also believed that wind driven firebrands may ignite the siding material itself. 


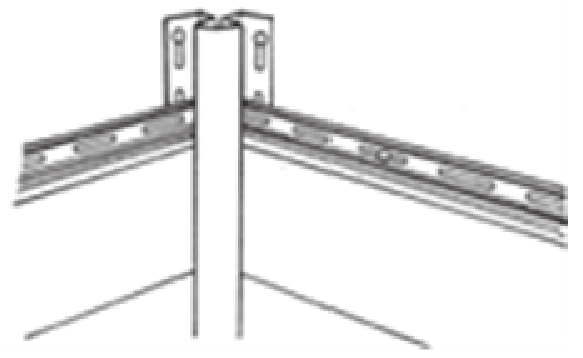

Figure 14 (a) Drawing of a corner post.

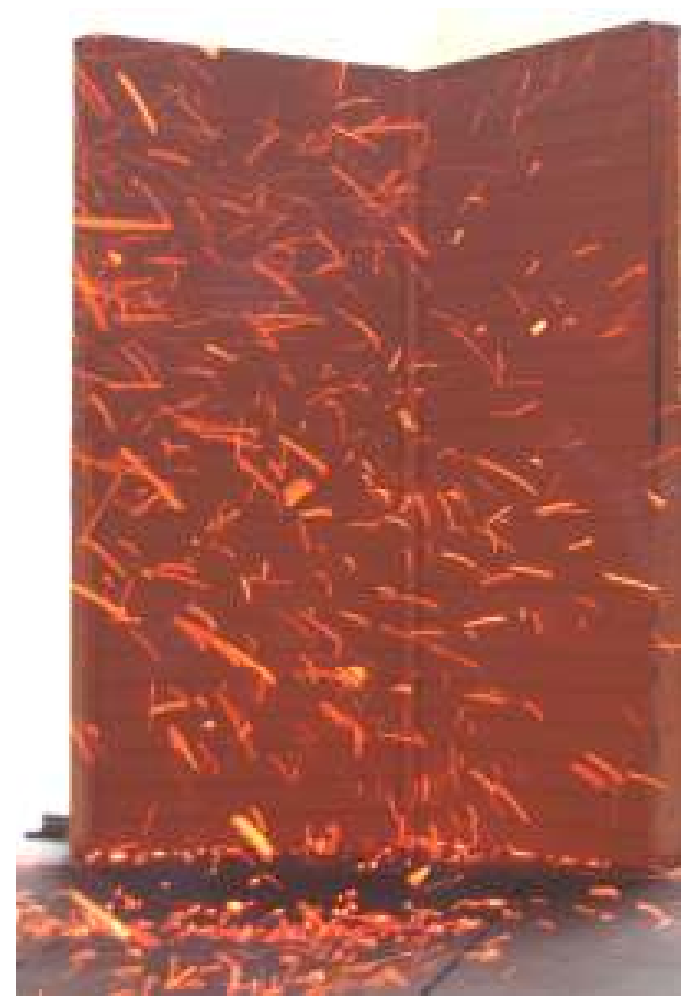

Figure 14 (b) Picture of vinyl siding corner assembly under firebrand bombardment.

Therefore, a parametric study was performed in an effort to quantify the range of conditions that siding treatments are vulnerable to ignition from firebrand showers. Three different siding treatments were used: vinyl siding, polypropylene siding, and cedar shingle siding (untreated and fire retardant treated). Detailed results for the vinyl and polypropylene siding were described in a recent conference publication; the cedar shingle siding results are presented in detail for the first time [29]. 
A full-scale re-entrant corner section (each side was $122 \mathrm{~cm}$ wide by $244 \mathrm{~cm}$ high) assembly was constructed for testing. To be able to control the moisture content of the OSB sheathing, the experiments were designed in a modular fashion. Specifically, each side of the $122 \mathrm{~cm}$ by $244 \mathrm{~cm}$ full section was comprised of 12 separate OSB pieces. This allowed each section to be oven dried and simply reassembled inside the custom mounting frame. For each assembly, a moisture barrier was applied (Tyvek ${ }^{1}$, a registered product of DuPont, was used for the vinyl and polypropylene siding; felt underlayment was used for the cedar siding) and then the siding treatments were applied. The frame was constructed using wood studs with a stud spacing of $406 \mathrm{~mm}$ (16") on center. The American Vinyl Siding Institute and the Cedar Shake and Shingle Bureau (wall manual) were consulted for proper installation and construction was performed in accordance with their respective installation manuals [30-31].

Similar to the roofing and vent studies, a starting velocity of $7 \mathrm{~m} / \mathrm{s}$ was selected since most of the firebrands produced from the Firebrand Generator were observed to be lofted under these conditions. The velocity was subsequently increased to $9 \mathrm{~m} / \mathrm{s}$ to ascertain if any the results were velocity dependent. Three replicate experiments were conducted for each wind speed.

For experiments with vinyl siding (see Figure 14b for typical experiment) conducted at 7 $\mathrm{m} / \mathrm{s}$ and $9 \mathrm{~m} / \mathrm{s}$, the firebrands were observed to melt the siding to the point where holes developed through the material. A picture of this is shown in Figure 15. While burns were observed in the moisture barrier at both wind speeds (Tyvek), ignition of the OSB sheathing was only observed for vinyl siding tests at $9 \mathrm{~m} / \mathrm{s}$ and when the sheathing was dried. It is important to

\footnotetext{
${ }^{1}$ Certain commercial entities, equipment, or materials may be identified in order to describe an experimental procedure or concept adequately. Such identification is not intended to imply recommendation or endorsement by the NIST, nor is it intended to imply that the entities, materials, or equipment are necessarily the best available for the purpose.
} 
point out that the OSB sheathing burned completely through and ignition was observed within the wood framing members as well $(2 \times 4)$.

For polypropylene siding, firebrands produced melting within the material but no holes were formed within the siding itself. Firebrands were observed to penetrate the corner post and burn holes into the moisture barrier (Tyvek) but ignition was never observed in the OSB sheathing for any wind speed of moisture content considered. Nevertheless, it is important to point out that firebrands easily penetrated the corner post in both siding types.

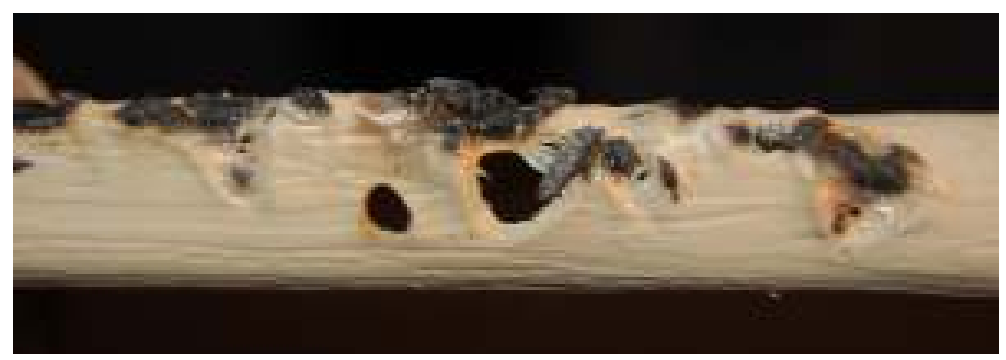

Figure 15 Image of vinyl siding (from bottom) after firebrand exposure at $7 \mathrm{~m} / \mathrm{s}$.

Experiments were conducted for untreated cedar shingle siding. Since it was not possible to dry the cedar shingle siding under full-scale experimental conditions, experiments were conducted by exposing the same re-entrant corner assembly to repeat exposures using the NIST Dragon. The moisture content of the cedar shingle siding at the time of testing was determined to be $11 \%$ on a dry basis (see equation $1 ; M_{w e t}$ and $M_{d r y}$ correspond to the weight and dry mass) and the wind tunnel speed was $7 \mathrm{~m} / \mathrm{s}$.

$$
\text { Moisture Content }=\frac{M_{w e t}-M_{d r y}}{M_{d r y}} * 100
$$

The exposure time of firebrands from the NIST Dragon is six minutes and it is possible to load the device and start a new experiment within ten minutes of completing the prior test; therefore three exposure tests can be conducted relatively quickly. After the first exposure, essentially 
nothing was observed to happen since the moisture of the cedar was too high to produce smoldering ignition. It was observed that after the third exposure to firebrand showers, the cedar shingle siding ignited at the base of the wall assembly. These results qualitatively demonstrate that continual firebrand bombardment may produce smoldering ignition of moist cedar, even under full-scale applications.

Finally, the vulnerability of fire retardant cedar shingles was investigated. The 2010 California Code of Regulations, Title 24, Part 2, Chapter 7A, that are effective January, 2011 allows fire-retardant-treated wood shingles listed for use as "Class B" roof covering (evaluated based on ASTM E108 [23]) as acceptable as an ignition-resistant wall covering material when installed over solid sheathing [26]. To the authors' knowledge, this new addition to the code was based on engineering judgment. To test the performance of this approach fire retardant cedar shingle siding was exposed firebrand showers. After repeated exposures to wind driven firebrand showers, no ignition of the cedar shingle siding material was observed.

Experiments were also conducted to determine if firebrands can produce ignition in fine fuels placed adjacent to the wall assembly and whether the subsequent ignition of fine fuels could lead to ignition of the wall assembly itself. In these experiments, vertical walls in addition to re-entrant corners were used. Dry pine tree needles were placed adjacent to the wall assembly to simulate fine fuels likely to be placed near a structure (such as pine straw mulch). The basis for using pine needles was predicated on the fire hazard expected from this fuel source observed in reduced-scale experiments. In prior work, using reduced-scale experiments, Manzello et al. [32] demonstrated that glowing firebrands are capable of producing smoldering ignition of pine needle beds, and under an applied air flow, SI of pine needle beds was observed to transition to FI. 
Firebrands were observed to ignite the needle bed via SI, the smoldering ignition become self-sustaining, and a transition to FI was observed (see Figure 16). The FI in the needles subsequently melted the vinyl siding and produced self-sustaining SI at the base of the wall assembly (within the OSB; this OSB was not even dried).
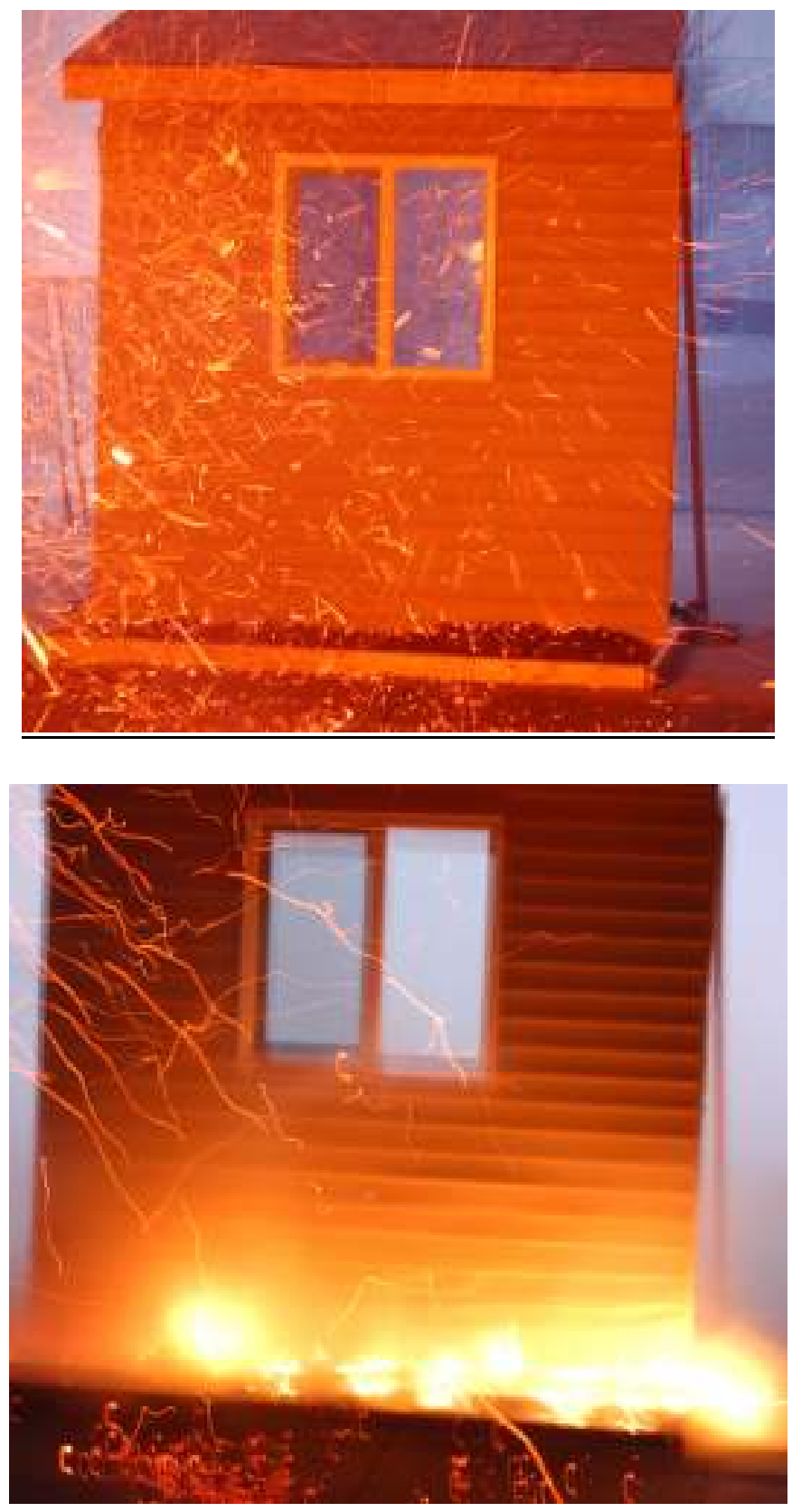

Figure 16 In the top image, firebrands have caused smoldering ignition in the mulch bed. In the bottom image, smoldering ignition has transitioned to flaming ignition and the wall assembly has ignited. 
When considering untreated cedar shingle siding, similar results were observed; namely ignition of the wall assembly itself (see Figure 17). The fire retarded cedar shingle siding performed very well. Even though the fine fuels exposed the wall assembly to flames, ignition of the cedar shingle siding was not observed, nor did any ignition occur in the OSB sheathing.

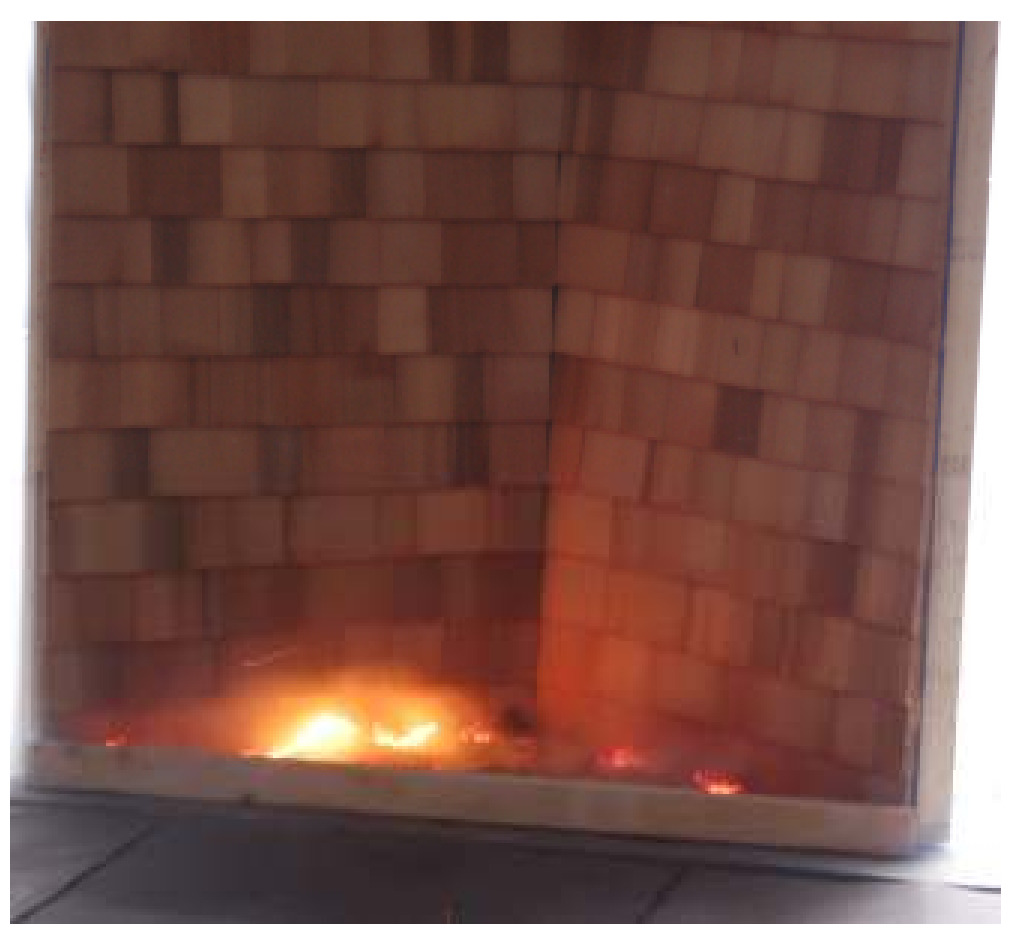

Figure 17 Images of untreated cedar shingle siding ignited under firebrand attack at a wind tunnel speed of $7 \mathrm{~m} / \mathrm{s}$.

\subsection{Eave Vulnerabilities}

An interesting question is whether firebrands may become lodged within joints between walls and the eave overhang. There are essentially two types of eave construction commonly used in California and the USA [33]. In open eave construction, the roof rafter tails extend beyond the exterior wall and are readily visible. In the second type of eave construction, known as boxed-in eave construction, the eaves are essentially enclosed and the rafter tails are no longer exposed. Since the open eave configuration is believed to be the most vulnerable to firebrand 
showers, some jurisdictions prone to intense WUI fires have required eaves be boxed-in. In both construction types, vents may be installed [33].

Consequently, the open eave construction, thought to the most vulnerable configuration situation, was used for experimentation. An eave with a total length of $122 \mathrm{~cm}$ overhang was constructed and mounted to a $2.44 \mathrm{~m}$ by $2.44 \mathrm{~m}$ wall assembly. While the eave was $122 \mathrm{~cm}$ long, the actual overhang used was $61 \mathrm{~cm}$. Since the purpose of these experiments was to determine if any accumulation of firebrands was observed within the eave assembly, the wall was simply fitted with OSB sheathing and it was not dried. The wall was constructed using wood framing members spaced $406 \mathrm{~mm}\left(16^{\prime \prime}\right)$ on center. Some of these results were presented in a recent conference publication [28].

In half of the experiments, no vent opening was used to simply observe if firebrands actually accumulated within the exposed rafters and subsequent joints (see Figure 18). In the remaining experiments, vents were installed (see bottom panel) and a mesh was placed within the vent opening (see Figure 18). For the vent openings, $50 \mathrm{~mm}$ holes were drilled into the blocking material and an $8 \times 8$ mesh $(2.75 \mathrm{~mm}$ opening $)$ was secured, as recommended in the new, 2010 California WUI code [26]. Three replicate experiments were performed. For the experiments that used no vent opening, firebrands were not observed to accumulate under the eave over the range of wind speeds considered (see Figure 19 for a typical experiment).

The NIST Fire Dynamics Simulator (FDS) was used to visualize the flow around the eave assembly in the FRWTF in an attempt to gain insight as to reasons why accumulation of firebrands were not observed under the eave assemblies for wind speeds of $7 \mathrm{~m} / \mathrm{s}$ and $9 \mathrm{~m} / \mathrm{s}$. The results of the simulations are presented in Figure 20. The dimensions of the eave assembly are identical to those used in the actual experiments and numerical grid spacing was $5 \mathrm{~cm}$. As 
mentioned, the flow profile inside the FRWTF was mapped using a series of hot wire anemometers (21 point array). Based on these measurements, the flow profile was observed to be uniform. As a result, in these simulations, the flow profile inside FRWTF was assumed uniform and fixed at $9 \mathrm{~m} / \mathrm{s}$.
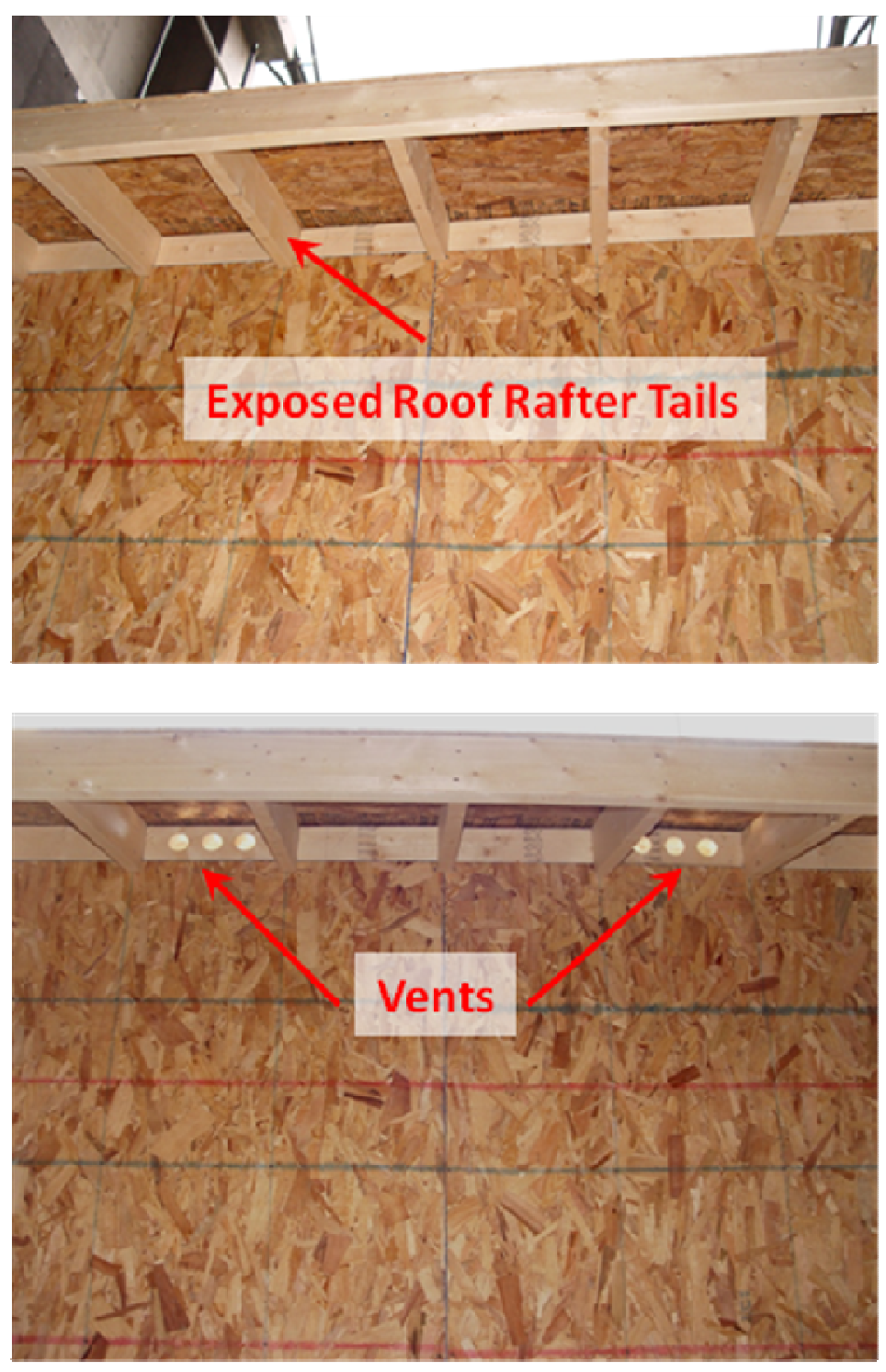

Figure 18 Images of open eave construction with no vents (top) and vents (bottom).

Although firebrands are not modeled, the resulting air flow profiles demonstrate why accumulation of firebrands was difficult under the eave (see Figure 20). Specifically, the presence of the wall results in a large stagnation zone in front of the wall that becomes more 
pronounced as wind speed was increased. In addition, under the eave there is an area of little or no flow velocity that would be required to drive the firebrands into the joints between the eave and wall assembly. It is important to point out that these simulations considered only airflow and do not include the seeding of firebrands into the flow. Current work at NIST is aimed at incorporating a firebrand transport model into FDS.

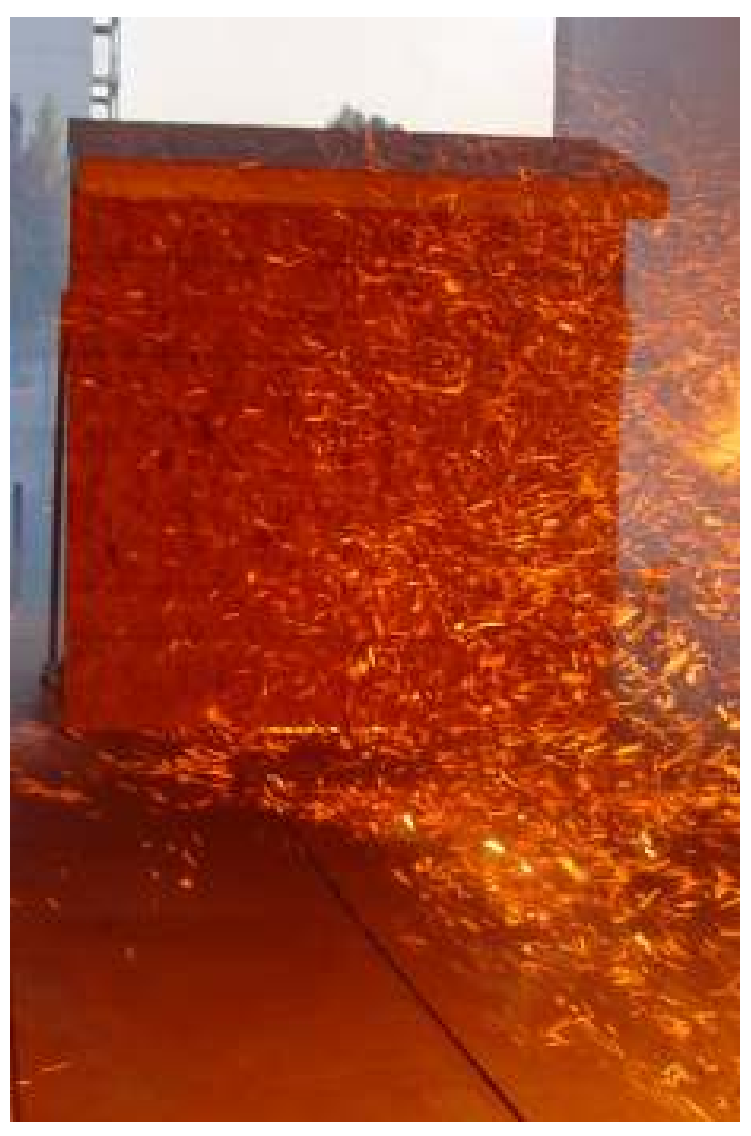

Figure 19 Image of wall fitted with eave under firebrand bombardment.

When vents were installed, cameras were placed both in front and behind of the eave assembly in order to quantify the number of firebrands arriving at the vent locations. At $7 \mathrm{~m} / \mathrm{s}$, the number of firebrands arriving at the vent location was $10 \pm 1$ (average \pm standard deviation). As the velocity was increased to $9 \mathrm{~m} / \mathrm{s}$, the total number of firebrands arriving at the vent 
location increased to $28 \pm 2$ (average \pm standard deviation). While the number of firebrands arriving at the vent locations increased as the wind speed increased, it was very small as compared to the number of firebrands that bombarded the wall/eave assembly.
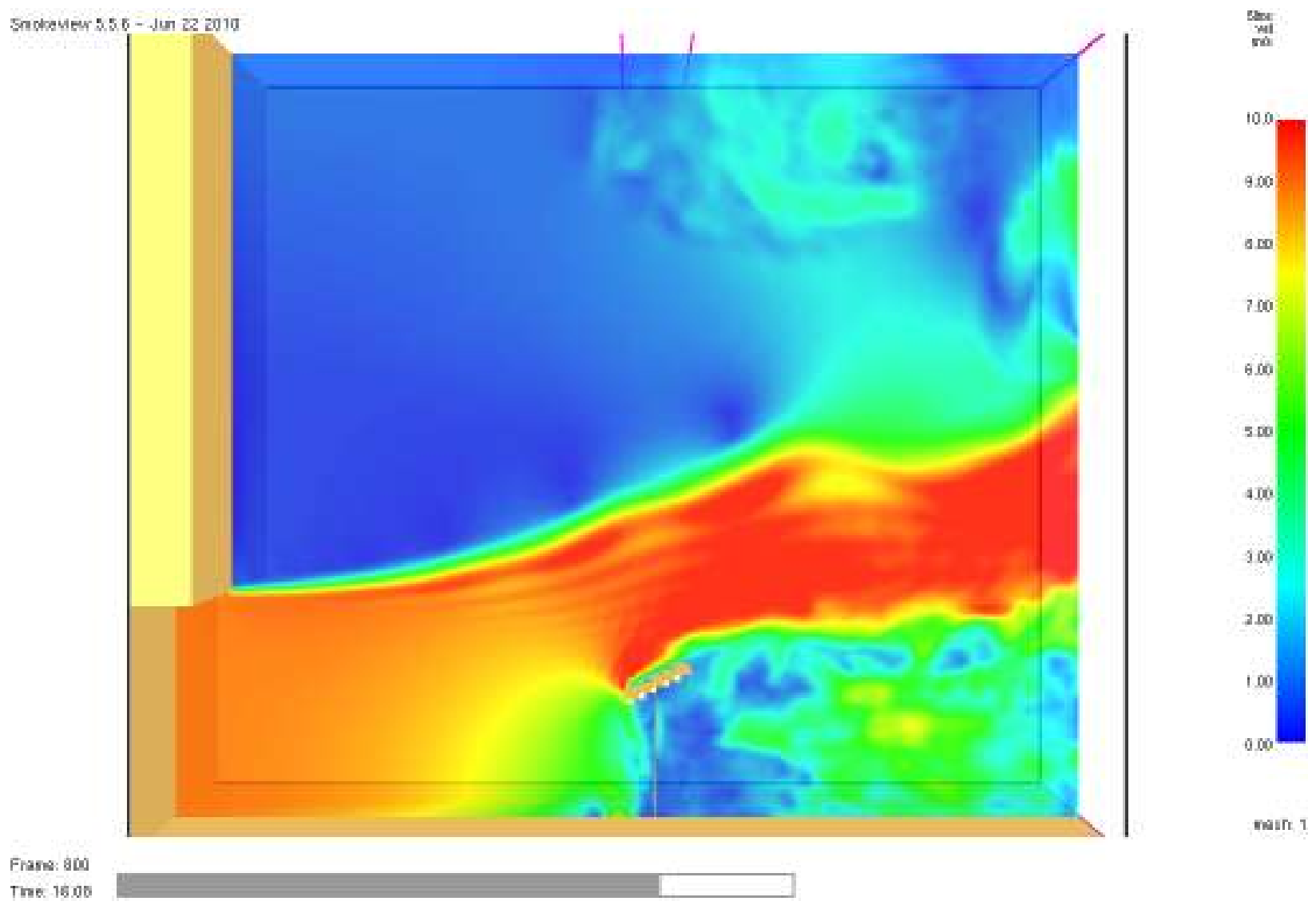

Figure 20 FDS simulations of air flow around eave assemblies for a wind speed of $9 \mathrm{~m} / \mathrm{s}$.

Firebrand entry into vents has long been thought to be important. Based on input garnered from the NIST workshop in California [28], for the present experiments using vents, it was desired to construct the wall from a combustible material to determine whether the wall itself could be ignited by firebrands within the time of the firebrand exposure (six minutes). Prior work by Manzello et al. $[15,18]$ used non-combustible construction to investigate only 
vent penetration and ignition of materials inside the structure. During the experiments conducted at $9 \mathrm{~m} / \mathrm{s}$, the base of the wall actually ignited due to the accumulation of firebrands. These experiments demonstrate that it was very easy to produce ignition outside the structure since many firebrands were observed to accumulate in front of the structure during the tests. Although some firebrands were observed to enter the vents, the ignition of the wall assembly itself demonstrates the dangers of wind driven firebrand showers and that if only firebrand resistant vents are used, other vulnerabilities around a structure must be considered. It must be noted that the base of the wall assembly ignited without the presence of other combustibles that may be found near real structures (e.g. mulch, vegetation). As discussed above, the presence of combustibles placed near the test wall only made ignition easier.

\subsection{Glazing Assembly Vulnerabilities}

For some time, it has been believed that firebrands become trapped, accumulate inside the corner of the framing of glazing assemblies, and may lead to window breakage. To investigate this potential vulnerability, two types of glazing assemblies were used for the experiments [34]. The first type was a horizontally sliding window assembly. The second type was a vertically sliding window assembly. Both of these glazing assemblies were double hung,

since it is also thought that this type of assembly could provide more locations for firebrands to accumulate. Double hung glazing assemblies are very common [28]. 


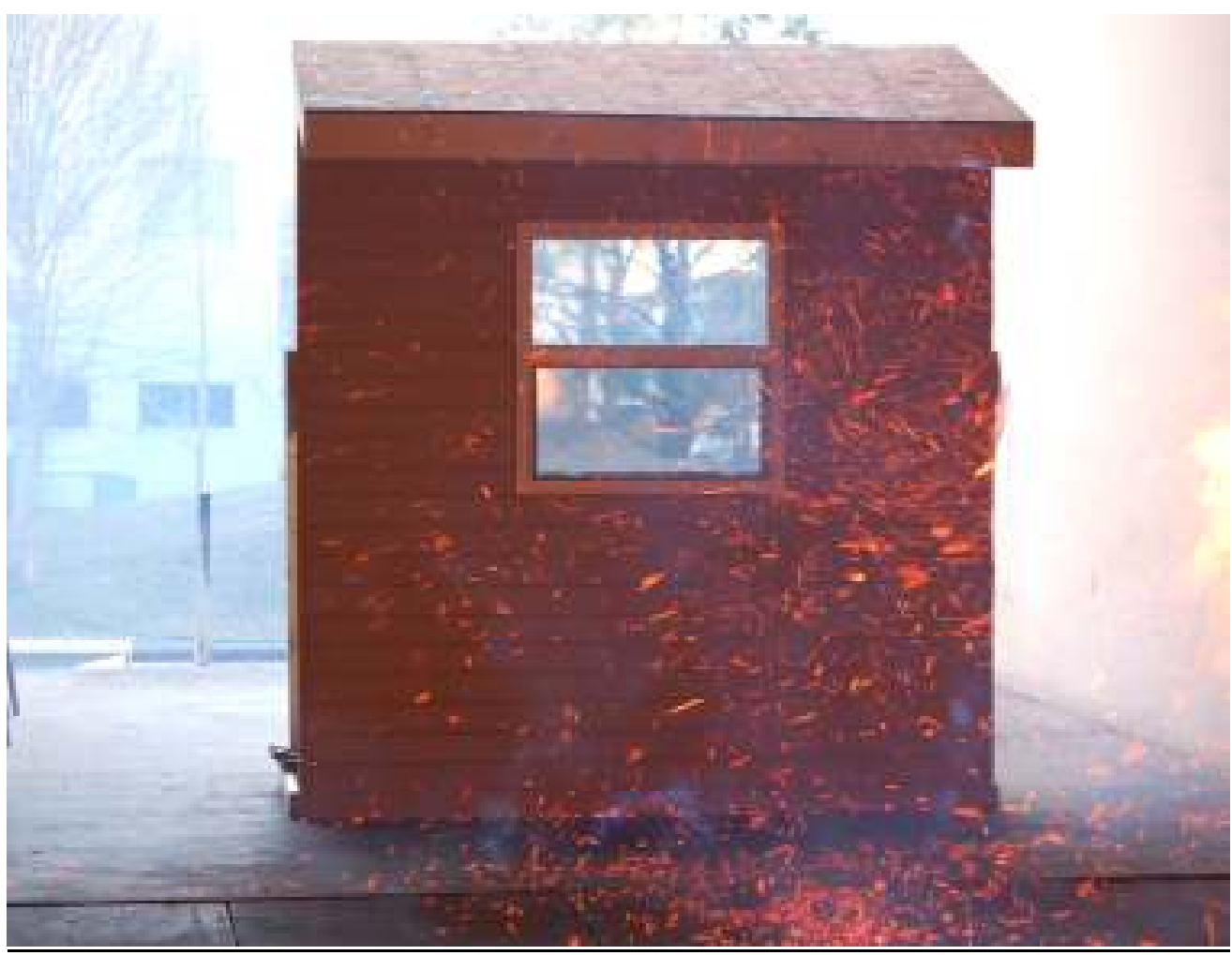

Figure 21 Picture of wall/eave assembly fitted with a vertically sliding, double hung window exposed to firebrand showers at a wind tunnel speed of $9 \mathrm{~m} / \mathrm{s}$.

The sizes of each of the glazing assemblies were the same: $91 \mathrm{~cm}$ by $91 \mathrm{~cm}$. To mount these assemblies, a $244 \mathrm{~cm}$ by $244 \mathrm{~cm}$ wall fitted with an open eave was constructed for testing. The wall was constructed using wood framing members spaced $406 \mathrm{~mm}$ (16") on center. OSB was applied over the wood framing members and a moisture barrier was installed over the OSB. Vinyl siding was applied over the moisture barrier. An eave with a total length of $122 \mathrm{~cm}$ was constructed and mounted to the wall assembly. For completeness, an image of a typical experiment is shown in Figure 21.

For, each window assembly considered, two different wind speeds were used. Specifically, the window assemblies were exposed to firebrand showers at wind tunnel speeds of $7 \mathrm{~m} / \mathrm{s}$ and $9 \mathrm{~m} / \mathrm{s}$. At $7 \mathrm{~m} / \mathrm{s}$, a majority of the firebrands produced from the NIST Dragon were observed to be carried with the flow and impinge on the wall assembly. It was observed that 
firebrands accumulated within the framing and this behavior was more pronounced for the vertically sliding glazing assembly; as suspected. Yet, in none of the experiments did the framing sustain sufficient damage for the window assembly to cause glass fallout and/or breakage.

\subsection{Firebrand Accumulation in Front of Obstacles}

In these experiments, an obstacle was placed downstream of the firebrand showers inside the FRWTF. The same obstacle was oriented differently to have a different aspect ratio and thus allow for qualitative comparison of firebrand flow and the resulting stagnation plane where firebrands could potentially accumulate. When oriented lower to the ground, the obstacle dimensions were $1.0 \mathrm{~m}$ high and $2.0 \mathrm{~m}$ wide; for a higher orientation, the obstacle dimensions were $2.0 \mathrm{~m}$ high and $1.0 \mathrm{~m}$ wide. The front face of the obstacle was constructed from calcium silicate board. The distance of the NIST Dragon from the obstacles was the same as the structure experiments, namely $7.5 \mathrm{~m}$ downstream. In front of the obstacles, a series of wood boards (thickness of $9 \mathrm{~mm}$ ) were placed flat on the ground of the FRWTF to determine if the accumulated firebrands were able to produce ignition events. The wood boards were not oven dried (moisture content $11 \%$ dry basis; see equation 1 for definition) in order to provide a greater barrier to produce ignition in these materials. A total of six experiments were conducted with three replicate tests for each obstacle orientation.

Figure 22 displays images of firebrands flowing around one of the obstacles used. The presence of the obstacle resulted in a stagnation plane where numerous firebrands were able to accumulate. After the firebrands were observed to accumulate, intense glowing combustion was observed and in all cases, the accumulated firebrands produced an ignition event (SI) in the wood 
samples. A series of photographs was also taken by increasing the exposure time on the camera to visualize the firebrand flow process over the obstacles. This image is shown in Figure 23.

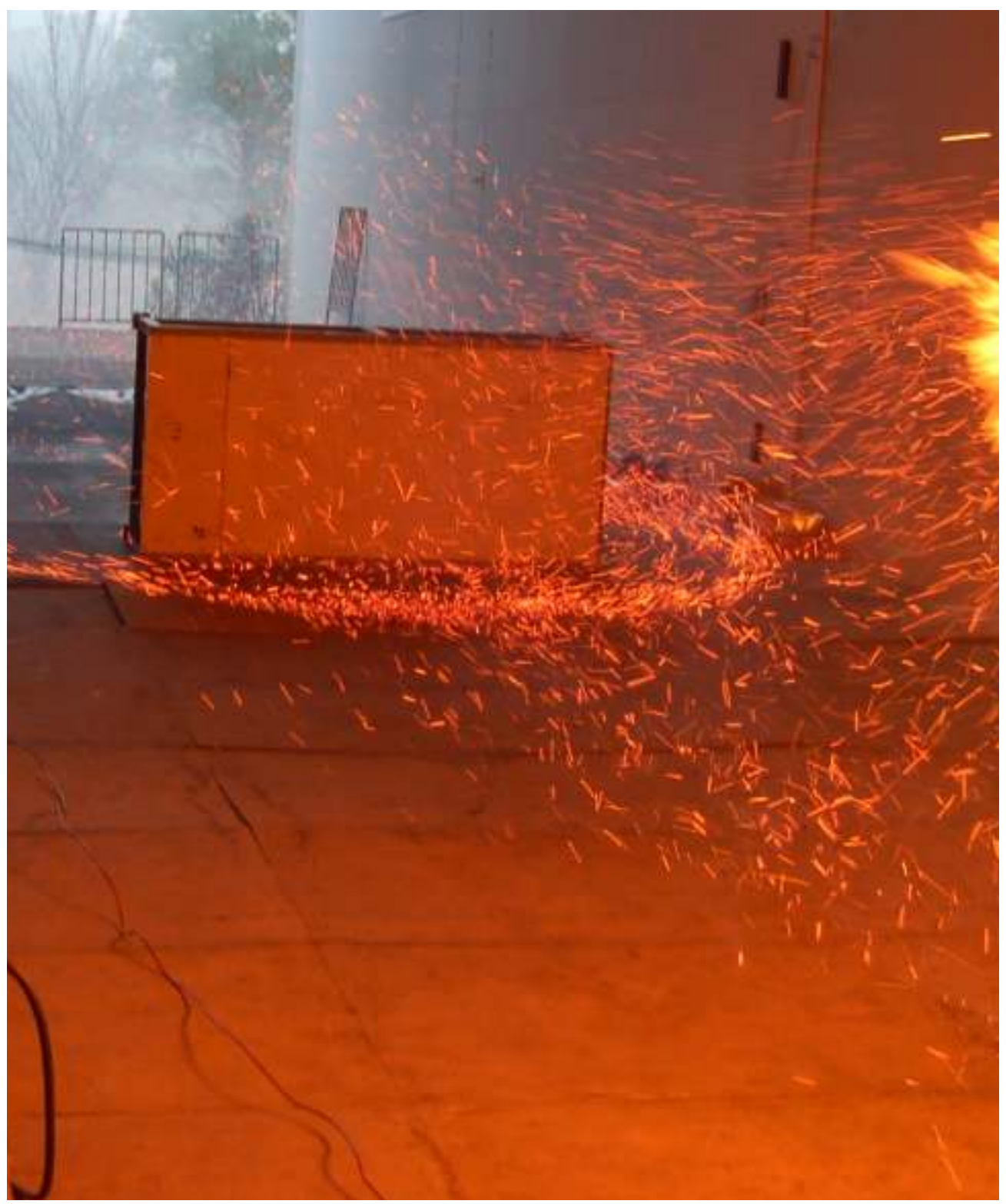

Figure 22 Image of firebrands flowing around one of the obstacles used.

FDS simulations were also performed to further elucidate this point [24]. These simulations are shown in Figure 24a-c. For completeness, in these simulations, the computational domain was the same as the BRI FTWTF (Figure 2a) and the grid size used was 
$5 \mathrm{~cm}$, The obstacles used were modeled as well as a very large obstacle; the same profile of the structure used ( $3 \mathrm{~m}$ by $3 \mathrm{~m}$ ). As can be seen, as the obstacle placed in the flow became lager, the recirculation and resulting stagnation plane became more intense. The experimental images qualitatively demonstrate this behavior.

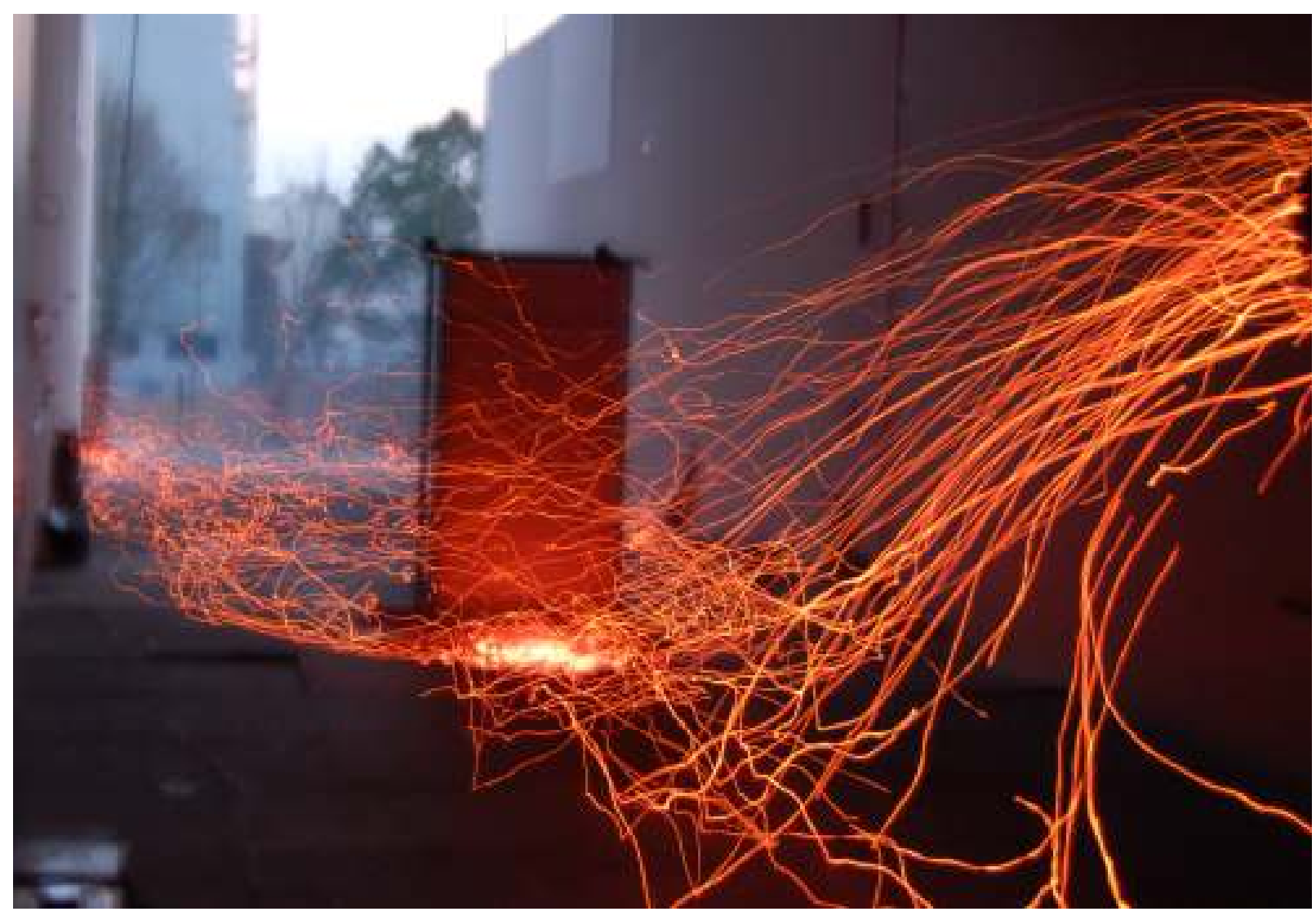

Figure 23 Photograph taken by increasing the exposure time on the camera to visualize the firebrand streaklines or flow over the obstacles. 


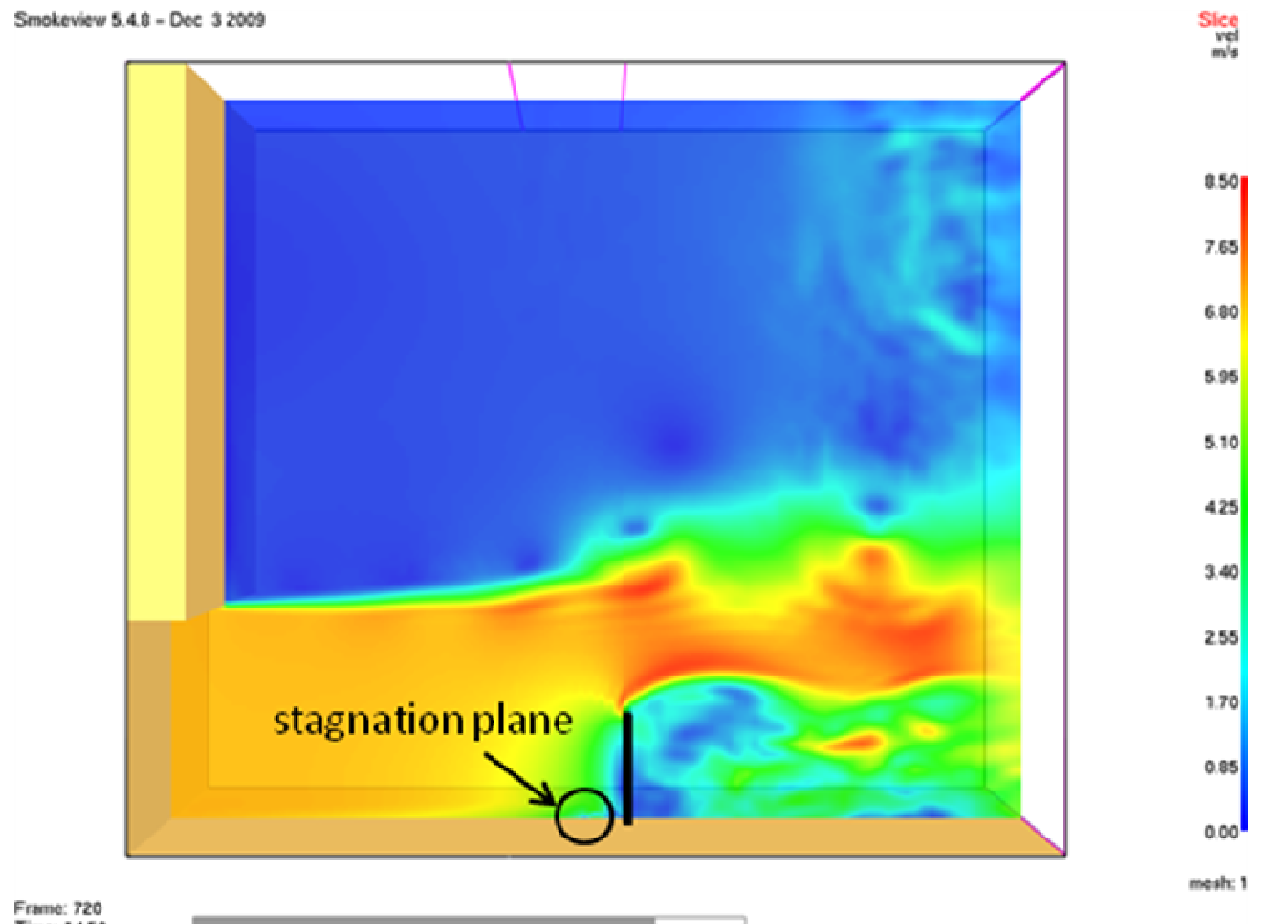

Figure 24 (a) Obstacle $1 \mathrm{~m}$ by $2 \mathrm{~m}$.

Smoteview 5.4 .8 - Dec 32009

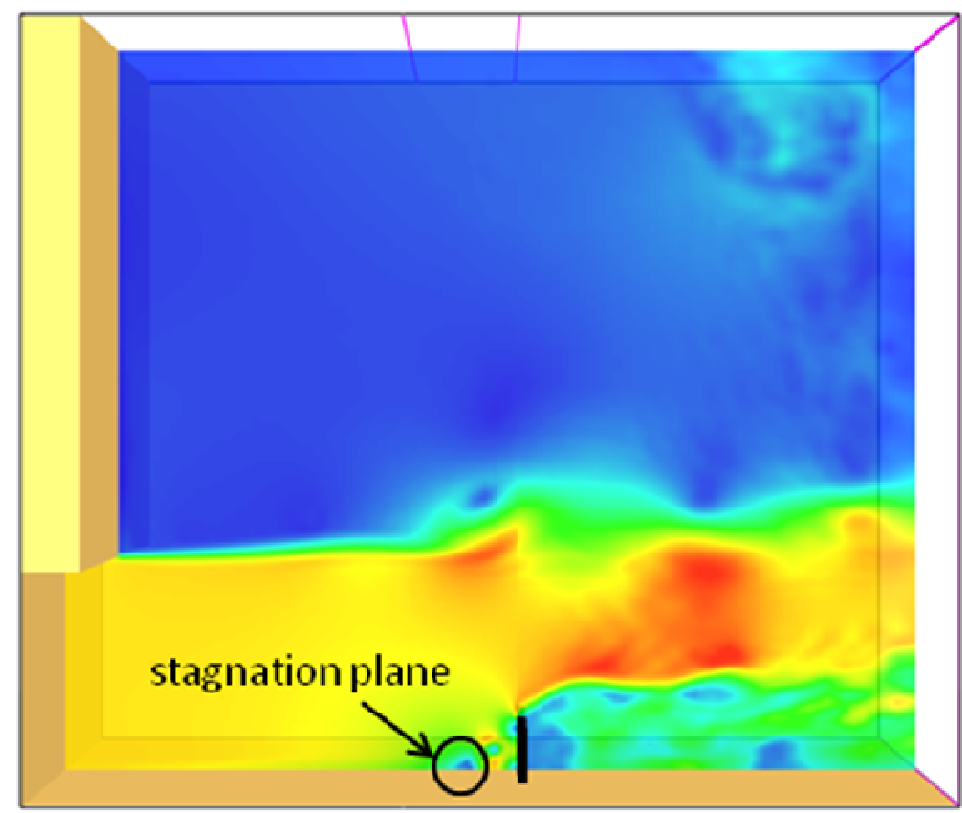

900
810
720
6.30
5.40
450
360
270
1.00
090
090
751

Figure 24 (b) Obstacle $2 \mathrm{~m}$ by $1 \mathrm{~m}$. 


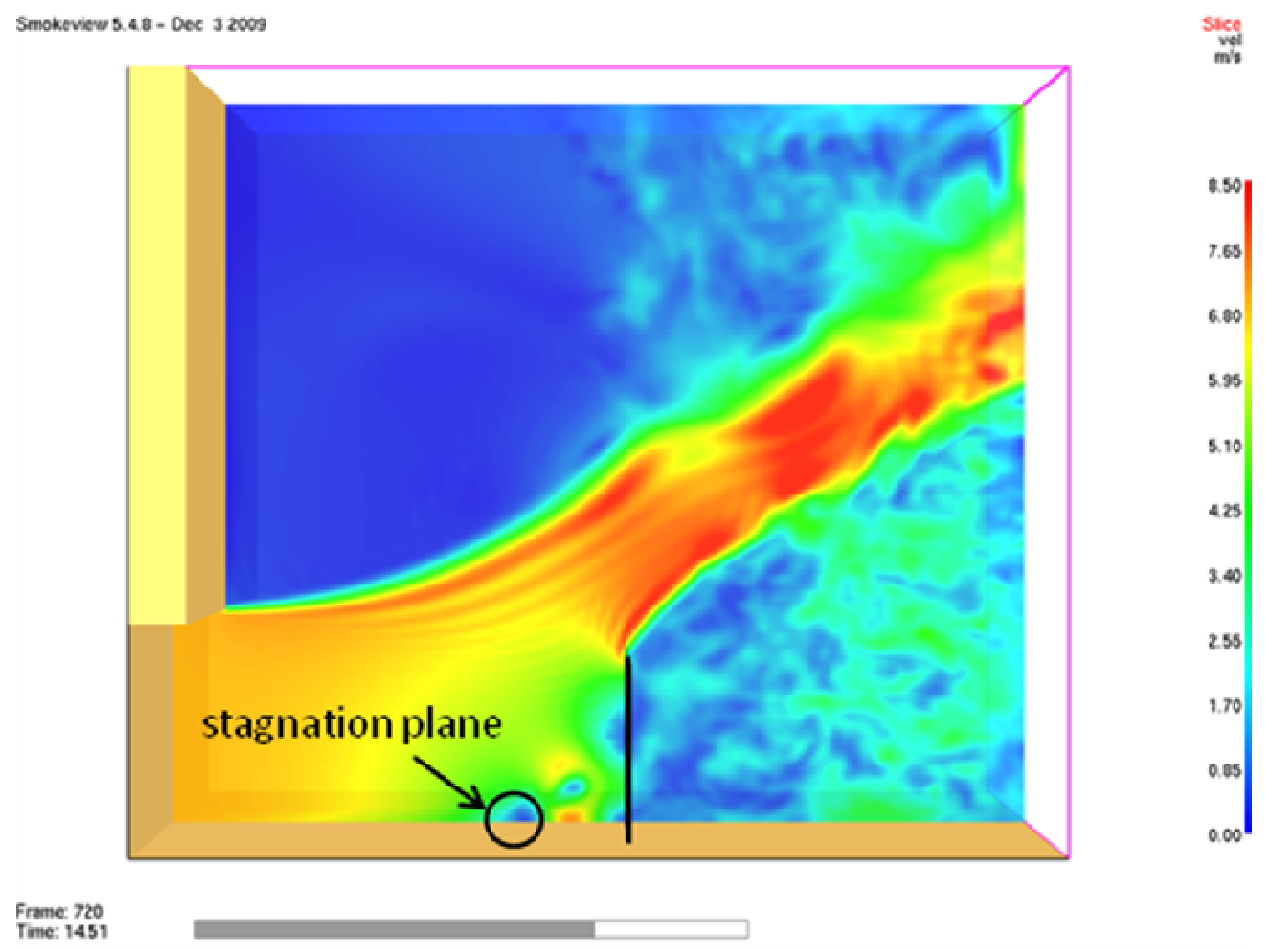

Figure 24 (c) Obstacle $3 \mathrm{~m}$ by $3 \mathrm{~m}$.

\subsection{Firebrand Production from Burning Structures and Structure Components}

As highlighted in the results discussed above, to date, the firebrand sizes generated by the NIST Dragon have been tied to those measured from full-scale tree burns and a real WUI fire (Angora) [21-22]. The Angora Fire firebrand data is believed to be the first such information quantified from a real WUI fire. Little data exists with regard to fire size distributions from actual structures or WUI fires. It is believed that the structures themselves may be a large source of firebrands, in addition to the vegetation. Yet, due to such limited studies, it cannot be determined if firebrand production from structures is similar to that of vegetation, or if firebrand production from structures is a significant source of firebrands in WUI fires.

To this end, in collaboration with the Northern California Fire Prevention Officers, (NORCAL FPO, a section of CALCHIEFS), a full-scale, proof-of-concept experiment was 
conducted to investigate firebrand production from a burning structure. More details are provided elsewhere [35].

In addition, wall and re-entrant corner assemblies were burned (constructed of OSB attached to wood studs) to collect firebrand data from structure components under wind in the BRI's FRWTF. Firebrand generation data from the full-scale structure burn conducted in Dixon, CA and structure component experiments conducted at the FRWTF were compared to examine the effect of an uncontrolled, full-scale situation on firebrand generation by simple controlled experiments.

The structure used for the experiments was a two story house located in Dixon, CA. Debris piles were used to ignite the structure and it took approximately two hours after ignition for complete burn down (see Figure 25 for pre-burn house pictures; see Figure 26 for first floor layout of the house). The picture of the house burn is shown in Figure 27. A large amount of water was poured onto the structure several times to control the fire since the house was located in downtown Dixon Firebrands were collected by using a series of water pans placed near (4 m) from the structure and on the road about $18 \mathrm{~m}$ downwind to the structure. After deposition into the water pans, the firebrands were filtered from the water using a series of fine mesh filters.

For comparison, three experiments were performed in BRI's FRWTF in Figure 28 by changing conditions shown in Table 2. A wall assembly and re-entrant corner assembly, shown in Figure 29, were used for experiments since they are typical residential construction in USA. Wood studs of both types of assemblies were spaced $40 \mathrm{~cm}$ on center and OSB was used as the exterior sheathing material. The assemblies were ignited using $\mathrm{T}$-shaped burner 10 minutes under no wind. The T-shaped burner was placed on the outside of assemblies since the purpose was to simulate ignition from outside an outside fire. After turning the burner off and the wind 
tunnel on, experiments were conducted until the wall assembly could no longer support itself. Firebrands were collected by using a series of water pans placed behind the assemblies. After deposition into the water pans, the firebrands were filtered from the water using a series of fine mesh filters. Firebrands were dried in an oven and the mass and size of each firebrand was measured by a precision balance and using digital image analysis, respectively. A figure of a full-scale re-entrant corner, ignited using a propane burner, and burning under an applied wind speed of $8 \mathrm{~m} / \mathrm{s}$ is shown if Figure 30.
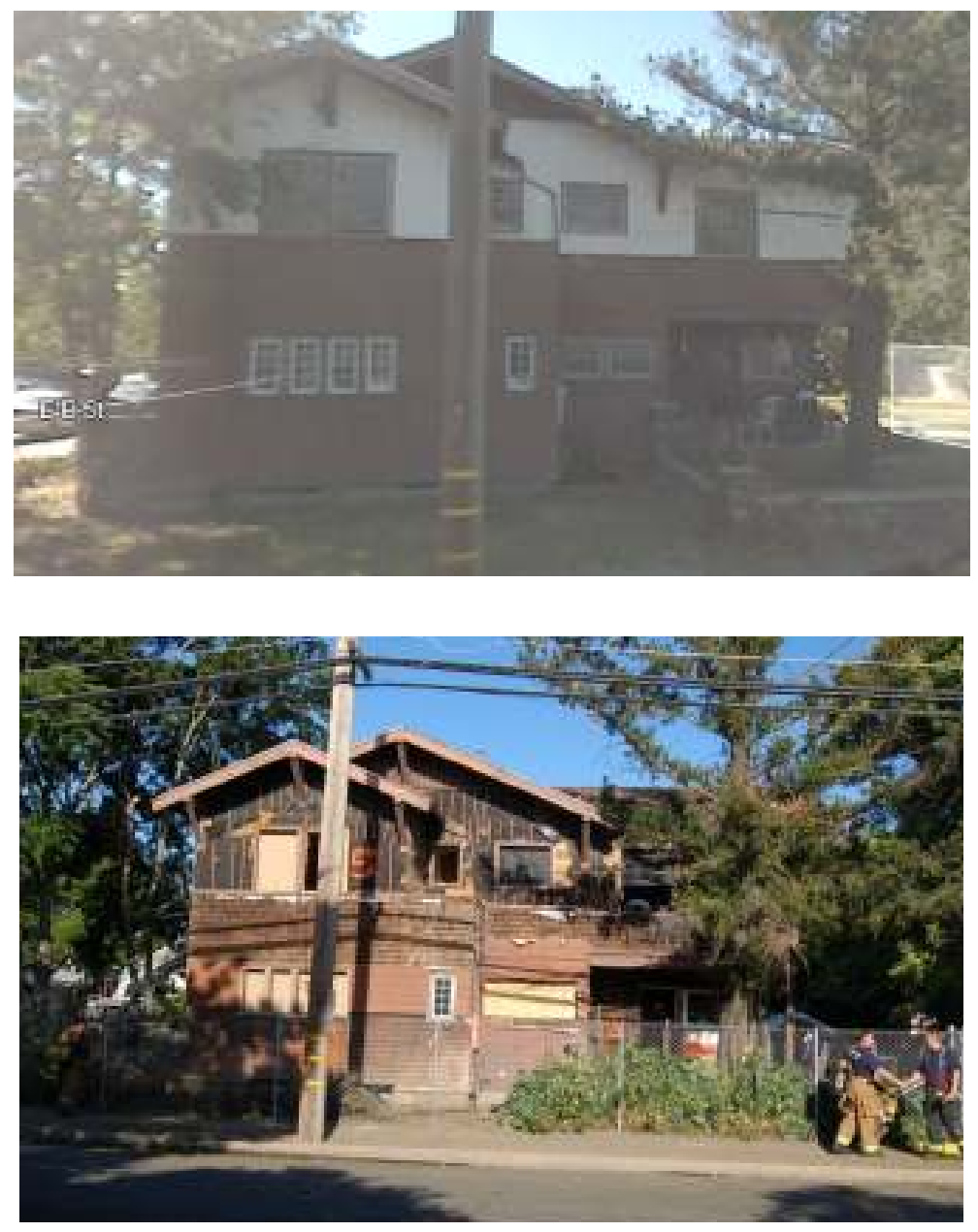

Figure 25 Pictures of burned structure from outside. Top: View from east side. Bottom: Prepared for burning 

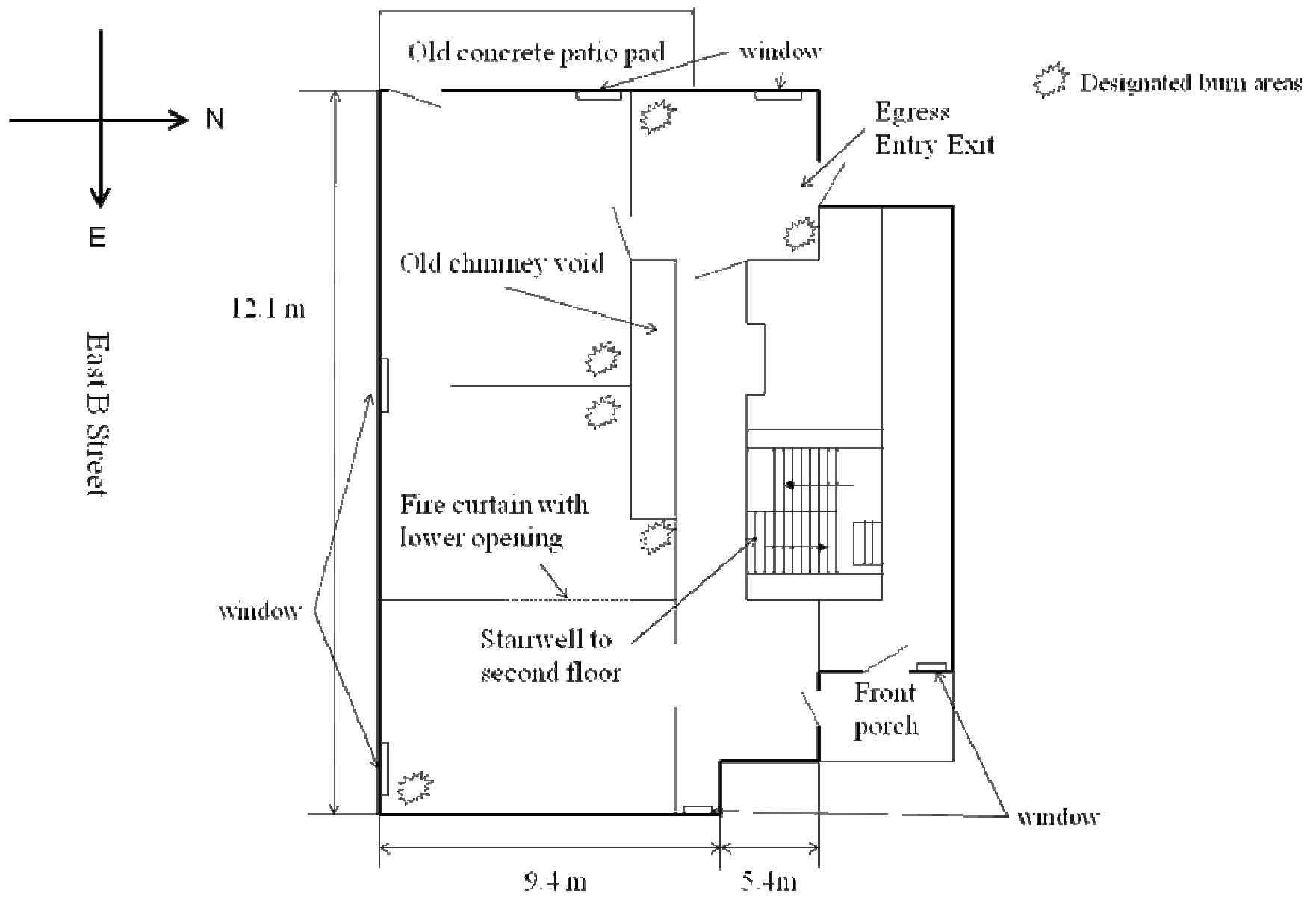

North 2ud Street

Figure 26 First floor plan of burned structure. 


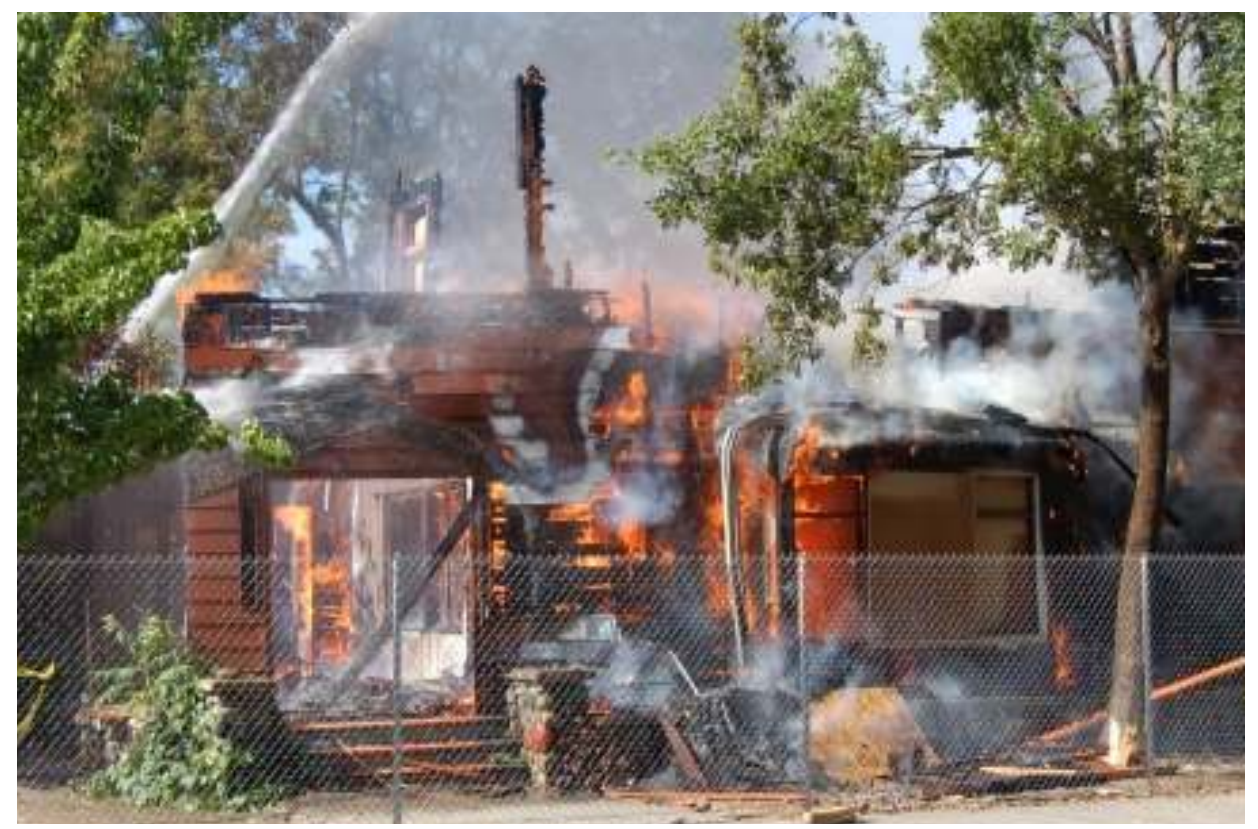

Figure 27 Picture of full-scale house burn used to collect firebrands.

Table II Summary of structure component tests at BRI's FRWTF.

\begin{tabular}{|c|c|c|c|}
\hline Experiment Number & $\begin{array}{c}\text { Experimental } \\
\text { Assemblies }\end{array}$ & Wind Speed (m/s) & Time to Finish (min) \\
\hline No. 1 & Wall Assembly & 6 & 30 \\
\hline No. 2 & $\begin{array}{c}\text { Re-entrant Corner } \\
\text { Assembly }\end{array}$ & 6 & 30 \\
\hline No. 3 & $\begin{array}{c}\text { Re-entrant Corner } \\
\text { Assembly }\end{array}$ & 8 & 6 \\
\hline
\end{tabular}




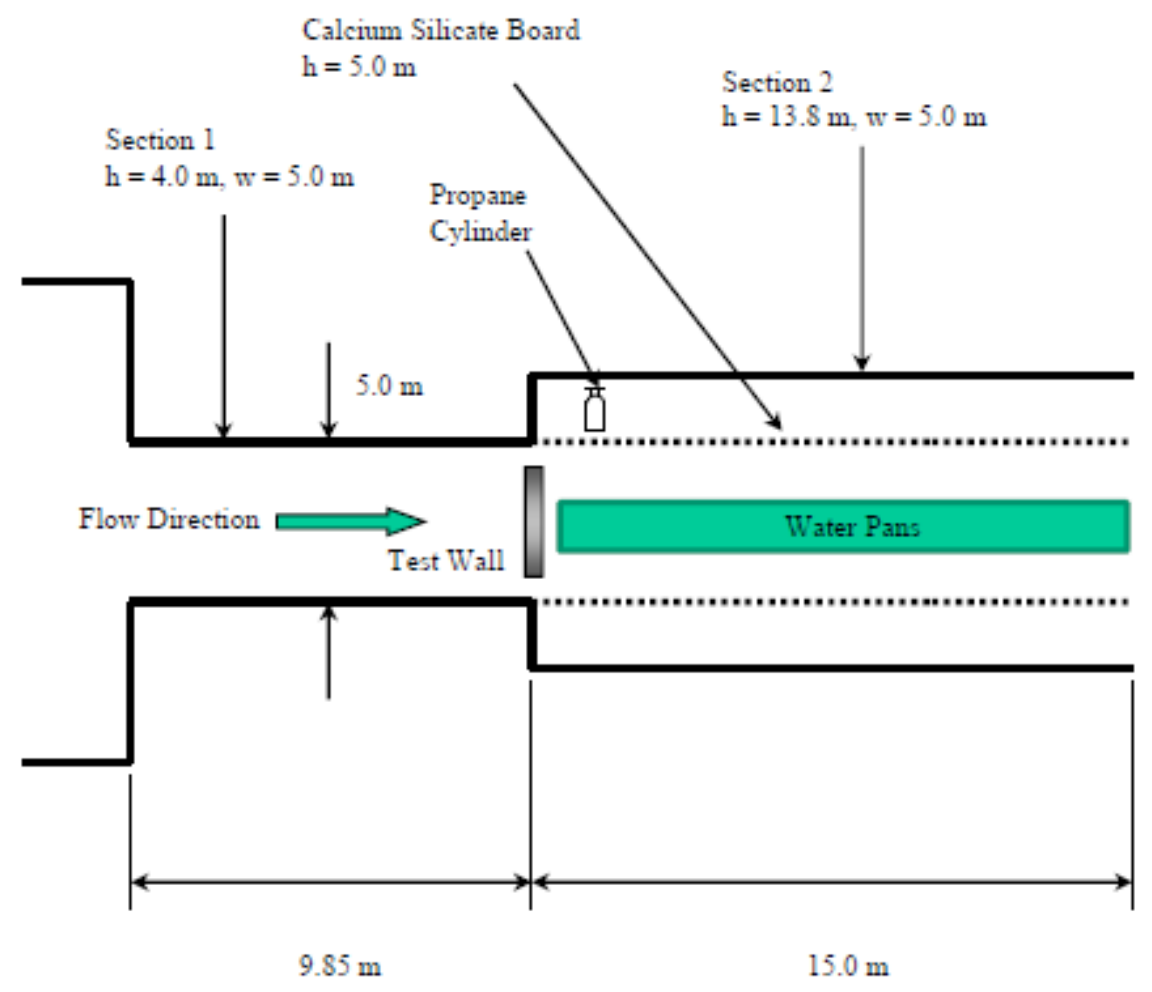

Figure 28 Schematic of FRWTF. The location of the wall assemblies used for firebrand generation experiments are shown.

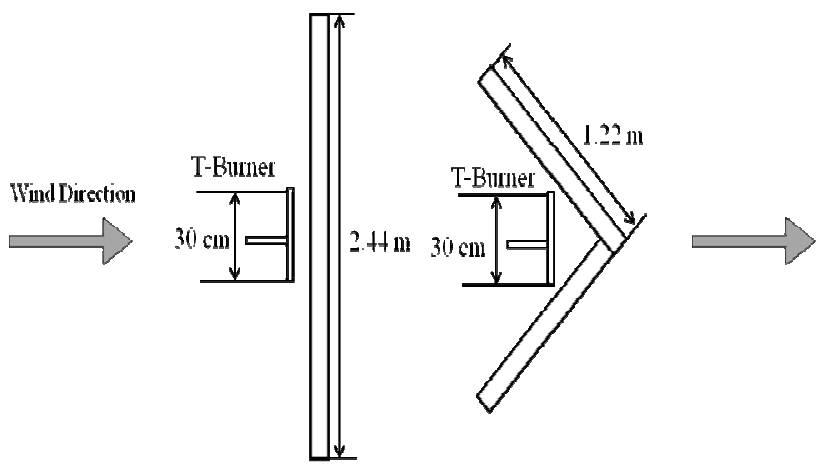

Figure 29 Schematic of Experimental Assemblies

Left: Wall Assembly, Right: Re-entrant Corner 


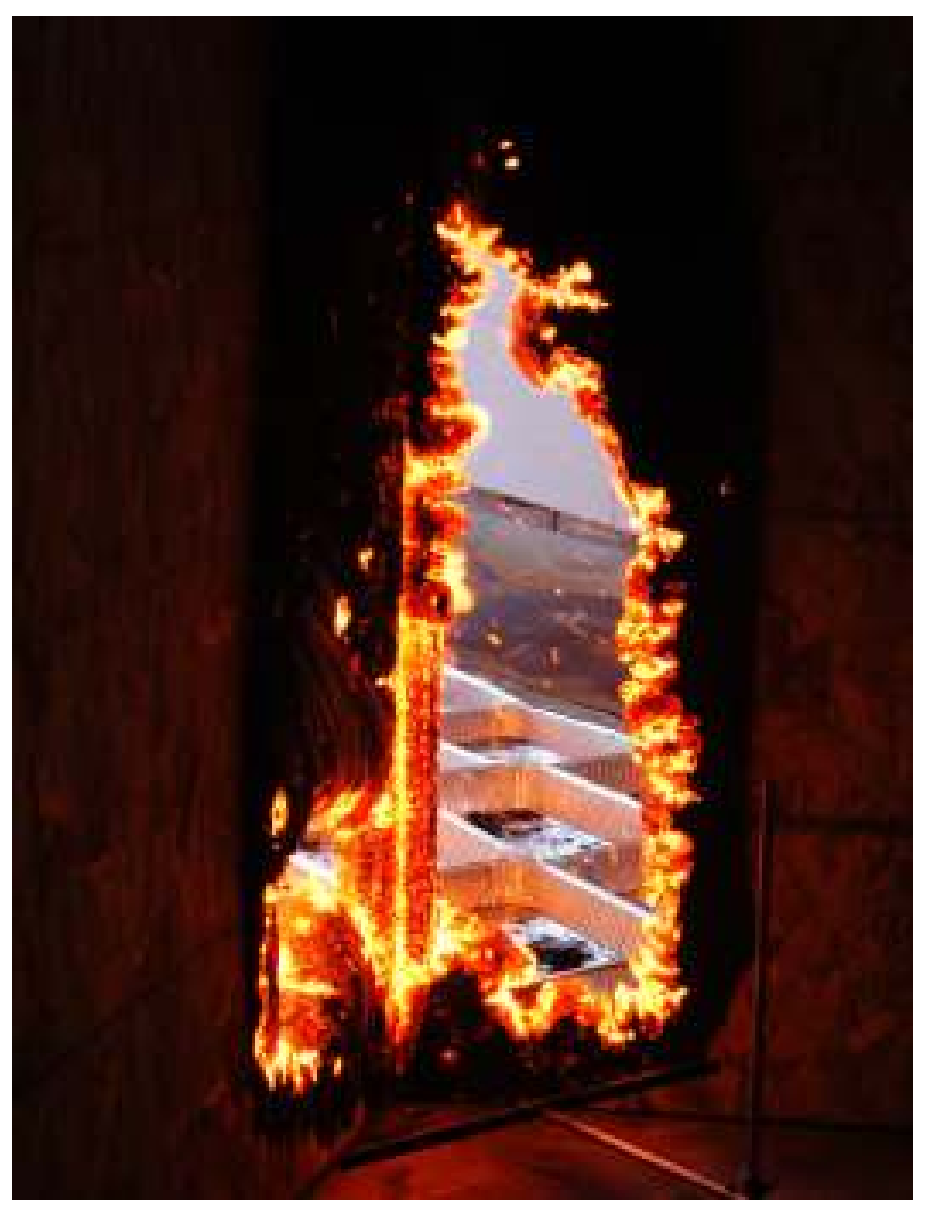

Figure 30 Firebrand generation from a burning re-entrant corner at $8 \mathrm{~m} / \mathrm{s}$ applied wind. Firebrands are produced on the backside of the assembly and are collected using an array of water pans downstream.

The firebrands collected both from the full-scale structure burn and structure components (wall/re-entrant corner assemblies) were compared with firebrand data from burning vegetation from Manzello et al. [21] and are shown in Figure 31. The data has been scaled to projected area for these comparisons. In Figure 31, firebrands greater than $40 \mathrm{~cm}^{2}$ projected area or with more than $5 \mathrm{~g}$ mass are eliminated for a detailed comparison (limited to only two such data). Figure 31 shows that the size and mass distribution of firebrands at two locations (collection location $4 \mathrm{~m}$ from a structure, the other collection location was $18 \mathrm{~m}$ downwind from structure) were similar. It was also observed that the size and mass distribution of firebrands from 
experiment No.2 and No.3 were quite similar while experiment No.1 had a larger variety of projected areas at a certain mass, especially within $10 \mathrm{~cm}^{2}$ projected area. The size distribution of firebrands collected from the full-scale structure and structure components were observed to have some similarities to those collected from vegetation (for small mass classes) as well as some differences. In some cases, the firebrands collected from the full-scale structure and the structure components were observed to have a larger projected area for similar mass classes, as compared to the vegetation firebrands. In addition, one firebrand with projected area larger than $50 \mathrm{~cm}^{2}$ area was found for the structure firebrands while all the vegetative firebrands reported by Manzello et al. [21] had less than $40 \mathrm{~cm}^{2}$ projected area.

Figure 32 shows that the size distribution of firebrands collected from a full-scale structure burn and wall and re-entrant corner assemblies compared with firebrand data from Vodvarka's study [36], in which Vodvarka measured firebrand size from a full-scale wooden house by using polyethylene sheets. It was found that most of firebrands from the full-scale structure used in the NIST study, both $18 \mathrm{~m}$ downwind from structure and $4 \mathrm{~m}$ from structure have less than $10 \mathrm{~cm}^{2}$ projected area. Most of firebrands from wall and re-entrant corner assemblies had less than $10 \mathrm{~cm}^{2}$ projected area at the same time the one from wall assembly had a relatively larger projected area than others. In addition, the size distribution of the firebrands in this study was larger and broader than those of Vovardka [36], in which most of firebrands was small, around $80 \%$ of them with less than $1 \mathrm{~cm}^{2}$ projected area. It is important to note that water was applied during the structure burn in Dixon, CA because this experiment was a part of fire fighter training exercise. It is not clear how water application may influence the firebrand size/mass produced as the structure burned. 
× Firebrands from $4.0 \mathrm{~m}$ Korean Pine

Firebrands from $2.6 \mathrm{~m}$ Dougras-Fir

Firebrands from $5.2 \mathrm{~m}$ Dougras-Fir

$\diamond \quad$ Experiment No. 1

$\square \quad$ Experiment No. 2

- Experiment No. 3

- Firebrands from $4 \mathrm{~m}$ from a structure

- Firebrands from $18 \mathrm{~m}$ downwind from structure

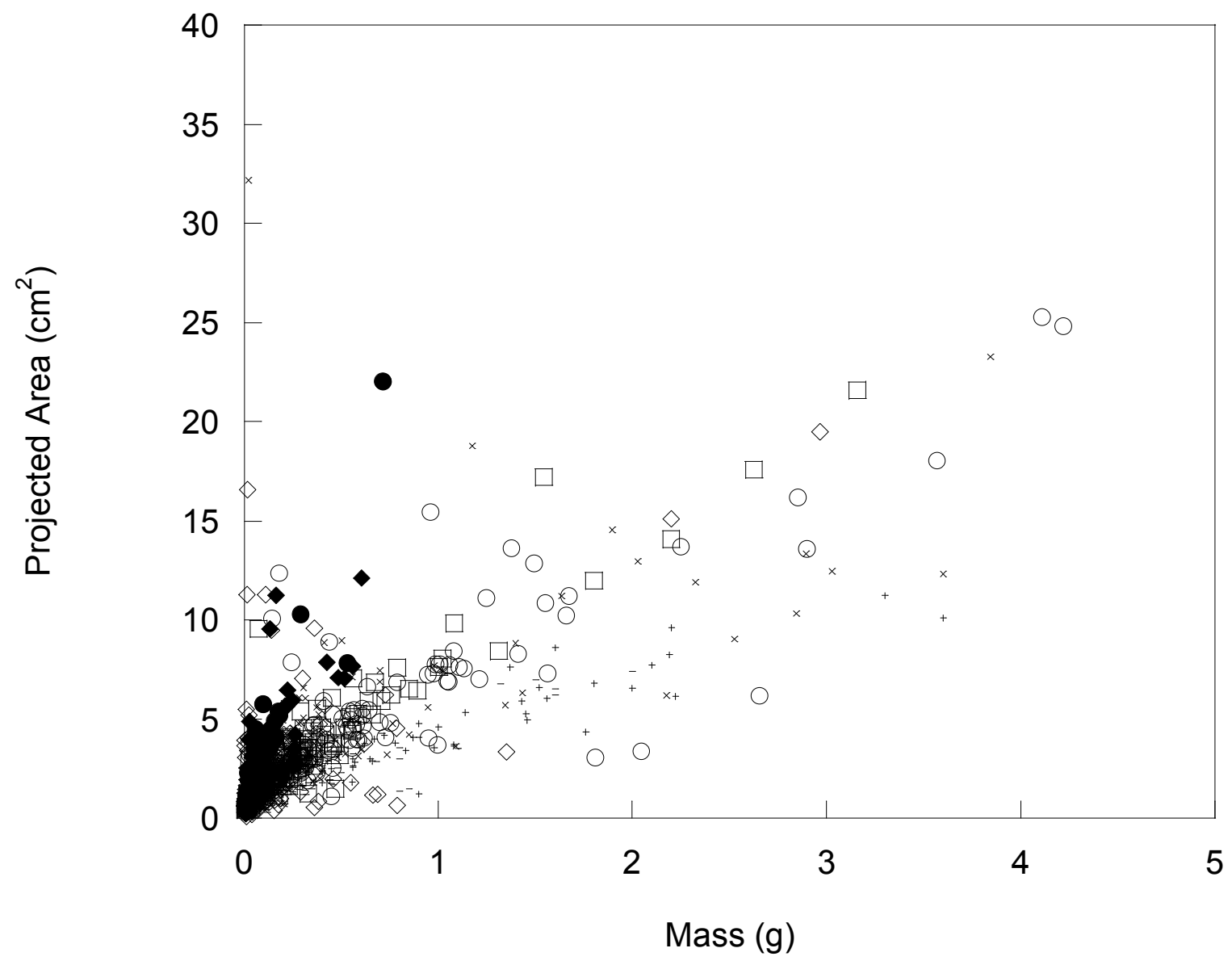

Figure 31 Size and Mass Distribution of Firebrands. 
Vodvarka

Experiment No. 1

$\square$ Experiment No. 2

$\square \quad$ Experiment No. 3

$\square$ Firebrands from $18 \mathrm{~m}$ from a structure

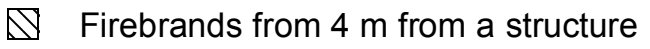

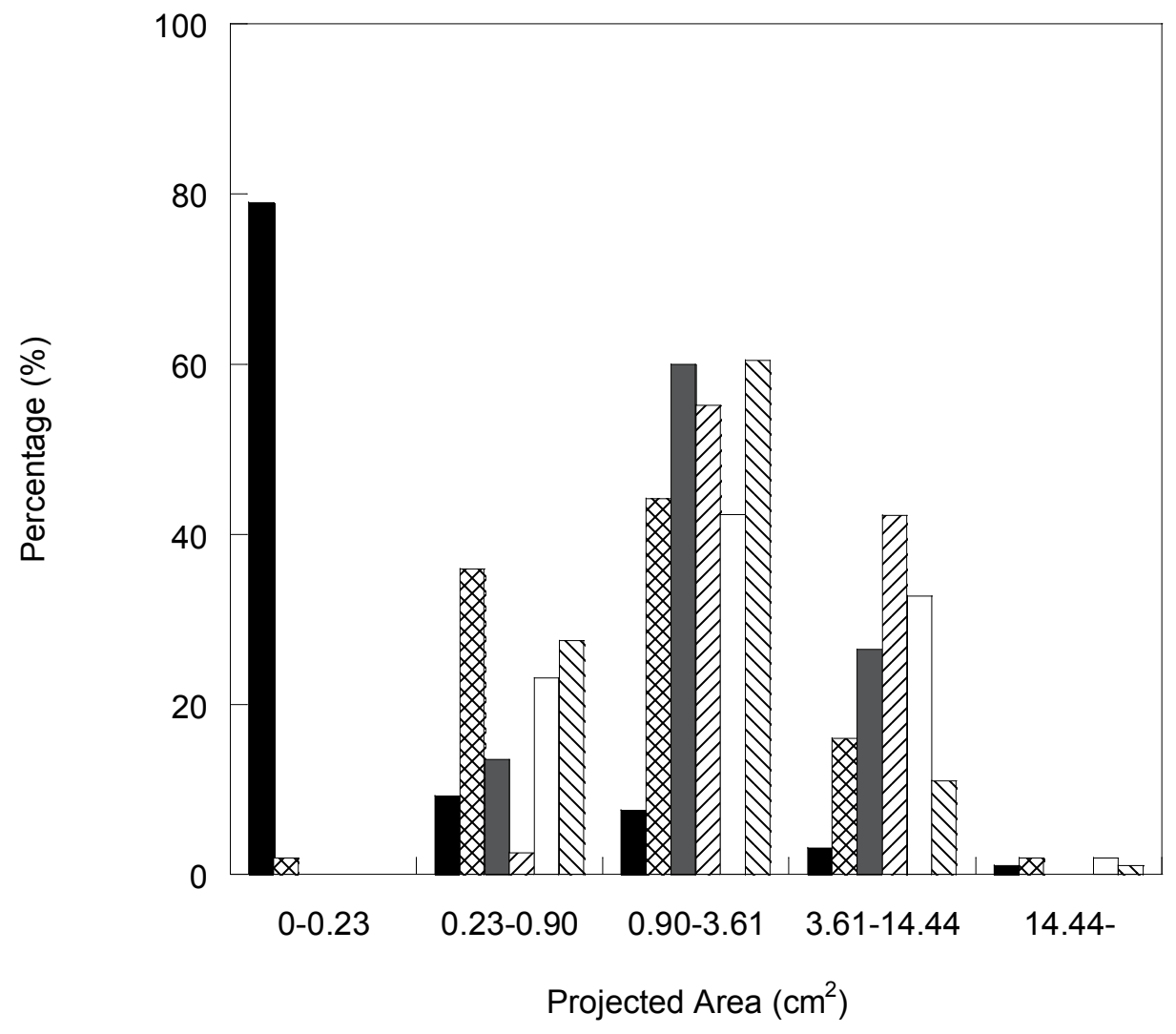

Figure 32 Size Distribution of Firebrands.

\subsection{General Remarks, Future Research, and Summary}

For the first time, it is possible to quantify vulnerabilities that structures have to firebrand showers on realistic scales. In real WUI fires, firebrand showers have been observed for several hours and with winds in excess of $20 \mathrm{~m} / \mathrm{s}$ [37]. It was not possible to conduct experiments using firebrand exposure for longer duration since this version of the NIST Dragon was not designed to operate continuously. Higher wind speeds could not be considered as well since the FRWTF 
was not designed to generate a wind field in excess of $10 \mathrm{~m} / \mathrm{s}$. In any event, the full-scale experiments summarized in this paper are the first to investigate these vulnerabilities in a parametric fashion and are important to demonstrate the dangers of firebrands and combustibles located too close to structures.

As part of future work, experiments are now planned to determine the vulnerabilities of decking assemblies to wind driven firebrand showers. A workshop was held recently to provide input to this upcoming experimental campaign for decking assemblies [38]. These experiments will make use of the newly developed full-scale continuous feed firebrand generator; capable of generating continuous firebrand showers.

It is desired that future work may consider exposures under higher wind speed as well as different firebrand size/mass distributions tied to various WUI exposures. Regarding the latter point, experiments are planned to determine firebrand production from burning structures inside BRI's FRWTF. The influence of wind speed will be considered by varying over a broad range. The data gathered from these upcoming experiments, in conjunction with the data presented in this report, will be used to compile the first comprehensive database of firebrand generation data. Such data will also enable the NIST Firebrand Generator to generate firebrand showers representative from burning structures.

It is worth noting the NIST Dragon technology has revolutionized WUI research and is being reproduced by other research laboratories. Specifically, the Insurance Institute for Business and Home Safety (IBHS) has used the NIST Dragon concept to generate firebrand showers in their full-scale wind tunnel facility [39]. With this pioneering research, it is now possible to bring the guesswork out of structure vulnerability to ignition from wind driven firebrand showers. 
Finally, while full-scale tests are necessary to highlight vulnerabilities of structures to firebrand showers, reduced-scale test methods afford the capability to test new firebrand resistant technologies and may serve as a basis for new standard testing methodologies. Therefore, Manzello recently developed NIST Dragon's LAIR (Lofting and Ignition Research) facility. The Dragon's LAIR is the only reduced-scale experimental facility capable of simulating wind driven firebrand showers at bench scale. The interested reader is referred elsewhere since a description of this facility is beyond the scope of this report [40]. This experimental facility has also been reproduced by ADAI at the University of Coimbra in Portugal, Europe's largest research group focused on WUI fires.

\subsection{Acknowledgments}

Mr. Yu Yamamoto and Mr. Takefumi Yoneki of the Tokyo Fire Department (Guest Researchers at BRI) are acknowledged for their support of these experiments during SLM's stay in Japan in 2008. Dr. William 'Ruddy’ Mell, Mr. Alexander Maranghides, Dr. Suel-Hyun Park,

Mr. John R. Shields, and Dr. Jiann C. Yang of NIST are acknowledged for many helpful discussions during the course of the work. The Science and Technology Directorate of the U.S. Department of Homeland Security sponsored the production of this material under Interagency Agreement IAA HSHQDC-10-X-00288 with the National Institute of Standards and Technology (NIST).

\subsection{References}

[1] Mitchell JW, Patashnik O (2007) Firebrand Protection as the Key Design Element for Structural Survival During Catastrophic Wildfire Fires. In Proceedings of Fire and Materials 2007 Conference, San Francisco, CA. 
[2] Blanchi R, Leonard JE, Leicester RH (2006) Lessons Learnt from Post-Fire Surveys at the Urban Interface in Australia. In Proceedings of the Fifth International Conference on Forest Fire Research, Figueria da Foz, Portugal.

[3] Maranghides A, Mell WE, (2009) A Case Study of a Community Affected by the Witch and Guejito Fires. NIST Technical Note 1635.

[4] Albini F (1983) Transport of Firebrands by Line Thermals. Combustion Science and Technology 32, 277-288.

[5] Muraszew A, Fedele JF (1976) Statistical Model for Spot Fire Spread. The Aerospace Corporation Report No. ATR-77758801 (Los Angeles, CA).

[6] Tarifa CS, del Notario PP, Moreno, FG (1965) On the Flight Paths and Lifetimes of Burning Particles of Wood Proceedings of the Combustion Institute 10, 1021-1037.

[7] Albini F (1979) Spot Fire Distances From Burning Trees - A Predictive Model. USDA Forest Service General Technical Report INT-56, Missoula, MT.

[8] Tarifa CS, del Notario PP, Moreno FG (1967) Transport and Combustion of Fire Brands. Instituto Nacional de Tecnica Aerospacial "Esteban Terradas", Final Report of Grants FG-SP 114 and FG-SP-146, Vol. 2. (Madrid, Spain).

[9] Tse SD, Fernandez-Pello AC (1998) On the Flight Paths of Metal Particles and Embers Generated by Power Lines in High Winds and Their Potential to Initiate Wildfires. Fire Safety Journal 30, 333-356.

[10] Woycheese JP (2000) Brand Lofting and Propagation for Large-Scale Fires. Ph.D. Thesis, University of California, Berkeley.

[11] Knight IK (2001) The Design and Construction of a Vertical Wind Tunnel for the Study of Untethered Firebrands in Flight. Fire Technology 37, 87-100.

[12] Anthenien R, Tse SD, Fernandez-Pello AC (2006) On the Trajectories of Embers Initially Elevated or Lofted by Small Scale Ground Fire Plumes in High Winds. Fire Safety Journal 41, 349-363.

[13] Himoto K, Tanaka, T (2005) Transport of Disk Shaped Firebrands in a Turbulent Boundary Layer. In D.T. Gottuk and B.Y. Lattimer (Eds.) Fire Safety Science - Proceedings of the Eigth International Symposium vol. 8, 433-444.

[14] Sardoy N, Consalvi JL, Kaiss A, Fernandez-Pello AC Porterie B (2008) Numerical study of ground-level distribution of firebrands generated by line-fires Combustion and Flame 154, 478488. 
[15] Manzello SL, Shields JR, Yang JC, Hayashi Y, Nii D (2007) On the Use of a Firebrand Generator to Investigate the Ignition of Structures in WUI Fires. In Proceedings of the $1 t^{\text {th }}$ International Conference on Fire Science and Engineering (INTERLFAM), Interscience Communications, London, pp. 861-872.

[16] Manzello SL, Shields JR, Hayashi Y, Nii D (2008) Investigating the Vulnerabilities of Structures to Ignition From a Firebrand Attack. In B Karlsson (Ed.) Fire Safety Science Proceedings of the Ninth International Symposium vol. 9, 143-154.

[17] Manzello SL, Hayashi Y, Yoneki Y, Yamamoto Y (2010) Quantifying the Vulnerabilities of Ceramic Tile Roofing Assemblies to Ignition During a Firebrand Attack. Fire Safety Journal 45, $35-43$.

[18] Manzello SL, Park SH, Shields JR, Suzuki S, Hayashi Y (2011)Experimental Investigation of Structure Vulnerabilities to Firebrand Showers. Fire Safety Journal 46, 568-578.

[19] Manzello SL, Shields JR, Cleary TG, Maranghides A, Mell WE, Yang, JC, Hayashi Y, Nii D, Kurita T (2008), On the Development and Characterization of a Firebrand Generator. Fire Safety Journal 43, 258-268.

[20] Manzello SL, Maranghides A, Mell WE (2007) Firebrand Generation from Burning Vegetation. International Journal of Wildland Fire 16, 458-462.

[21] Manzello SL, Maranghides A, Shields JR, Mell WE, Hayashi Y, Nii D (2009), Mass and size distribution of firebrands generated from burning Korean pine (Pinus koraiensis) trees. Fire and Materials Journal 33, 21-31.

[22] Foote EID, Liu J, and Manzello SL (2011) Characterizing Firebrand Exposure During Wildland Urban Interface Fires. In Proceedings of Fire and Materials 2011 Conference, Interscience Communications, London.

[23] Standard Test Methods for Fire Tests of Roof Coverings, ASTM E108, American Society for Testing and Materials, West Conshohocken, PA.

[24] California Building Code, Title 24, Part 2, Chapter 7A, 2007 (http://www.bsc.ca.gov/default.htm).

[25] McGrattan K, McDermott R, Hostikka S, Floyd J (2010) Fire Dynamics Simulator (Version 5) User's Guide. NIST Special Publication 1019-6.

[26] California Building Code, Title 24, Part 2, Chapter 7A, 2010 (http://www.bsc.ca.gov/default.htm).

[27] Official minutes ASTM E05.14 External Fire Exposure, June 17, 2009 (http://www.astm.org). 
[28] Manzello SL, Suzuki S (2010) Summary of Workshop on Research Needs for Full-scale Testing to Determine Vulnerabilities of Siding Treatments and Glazing Assemblies to Ignition by Firebrand Showers. NIST Special Publication 1111.

[29] Manzello SL, Suzuki S, Hayashi Y (2011) Exposing Siding Treatments and Walls Fitted with Eaves to Firebrand Showers. In Proceedings of Fire and Materials 2011 Conference, Interscience Communications, London.

[30] Vinyl Siding Installation Manual (2007) Vinyl Siding Institute.

[31] Exterior and Interior Wall Manual (2004) Cedar Shake and Shingle Bureau.

[32] Manzello SL, Cleary TG, Shields JR, Yang JC (2006) Ignition of mulch and grasses by firebrands in wildland -urban interface (WUI) fires. International Journal of Wildland Fire 15, 427-431.

[33] Quarles S.L, Valachovic Y, Nakamura, G, Nader G, De Saux MJ (2010) Home Survival in Wild Fire Prone Areas: Building Materials and Design Considerations. ANR Publication 8393.

[34] Manzello SL, Suzuki S, Hayashi Y (2011) Exposing Glazing Assemblies to Firebrand Showers. In Proceedings of JAFSE (Japan Association for Fire Science and Engineering) Annual Symposium (2011) pp. 214-215, Tokyo, Japan.

[35] Suzuki S, Manzello SL (2011) Characteristics of heat flux and firebrand generation data obtained from a full-scale structure burn. in: Proceedings of Japan Association for For Science and Engineering JAFSE Annual Symposium, 418-419, Tokyo, Japan.

[36] Vodvarka FJ, Firebrand field studies - IIT Research Institute, Chicago, IL. (1969) 33 p.

[37] Mitchell JW (2009) Power Lines and Catastrophic Wildland Fire in Southern California. In Proceedings of the 11th International Conference on Fire and Materials pp. 225-238, San Francisco, CA.

[38] Manzello SL, Suzuki, S (2011) Summary of 2011 Workshop on Research Needs for Fullscale Testing to Determine Vulnerabilities of Decking Assemblies to Ignition by Firebrand Showers. NIST Special Publication 1129.

[39] http://www.disastersafety.org.

[40] Manzello SL and Suzuki (2011) The New and Improved NIST Dragon's LAIR (Lofing and Ignition Research) Facility. Fire and Materials Journal. doi: 10.1002/fam.1123, to appear. 